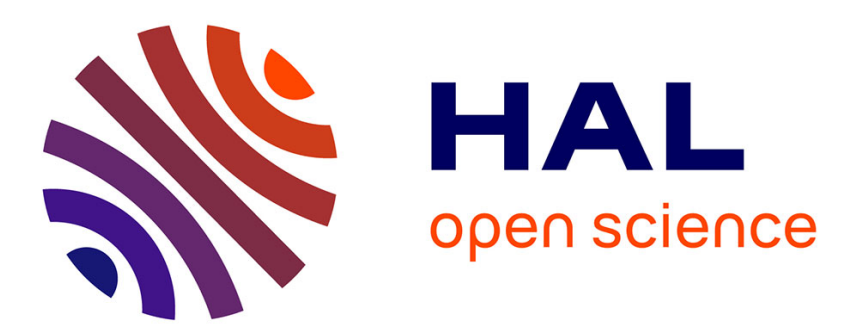

\title{
RNA Chaperones Hfq and ProQ Play a Key Role in the Virulence of the Plant Pathogenic Bacterium Dickeya dadantii
}

Simon Leonard, Camille Villard, William Nasser, Sylvie Reverchon, Florence Hommais

\section{To cite this version:}

Simon Leonard, Camille Villard, William Nasser, Sylvie Reverchon, Florence Hommais. RNA Chaperones Hfq and ProQ Play a Key Role in the Virulence of the Plant Pathogenic Bacterium Dickeya dadantii. Frontiers in Microbiology, 2021, 12, pp.687484. 10.3389/fmicb.2021.687484 . hal-03336963

\section{HAL Id: hal-03336963 https://hal.science/hal-03336963}

Submitted on 8 Nov 2021

HAL is a multi-disciplinary open access archive for the deposit and dissemination of scientific research documents, whether they are published or not. The documents may come from teaching and research institutions in France or abroad, or from public or private research centers.
L'archive ouverte pluridisciplinaire HAL, est destinée au dépôt et à la diffusion de documents scientifiques de niveau recherche, publiés ou non, émanant des établissements d'enseignement et de recherche français ou étrangers, des laboratoires publics ou privés. 


\section{OPEN ACCESS}

Edited by:

Daniela De Biase,

Sapienza University of Rome, Italy

Reviewed by:

Lucy N. Moleleki,

University of Pretoria, South Africa

Sébastien Bontemps-Gallo,

Institut Pasteur de Lille, France

Marta Potrykus,

Medical University of Gdańsk, Poland

*Correspondence:

Florence Hommais

florence.hommais@univ-lyon1.fr

Sylvie Reverchon

sylvie.reverchon-pescheux@insa-

lyon.fr

Specialty section:

This article was submitted to Microbial Physiology and Metabolism, a section of the journal

Frontiers in Microbiology

Received: 29 March 2021

Accepted: 31 May 2021

Published: 24 June 2021

Citation

Leonard S, Villard C, Nasser W Reverchon $S$ and Hommais $F$ (2021) RNA Chaperones Hfq and ProQ Play

a Key Role in the Virulence of the

Plant Pathogenic Bacterium Dickeya dadantii. Front. Microbiol. 12:687484.

doi: 10.3389/fmicb.2021.687484

\section{RNA Chaperones Hfq and ProQ Play a Key Role in the Virulence of the Plant Pathogenic Bacterium Dickeya dadantii}

\author{
Simon Leonard, Camille Villard, William Nasser, Sylvie Reverchon* and \\ Florence Hommais*
}

Université de Lyon, INSA Lyon, Université Claude Bernard Lyon 1, CNRS, UMR 5240 MAP, Microbiologie, Adaptation,

Pathogénie, Villeurbanne, France

Dickeya dadantii is an important pathogenic bacterium that infects a number of crops including potato and chicory. While extensive works have been carried out on the control of the transcription of its genes encoding the main virulence functions, little information is available on the post-transcriptional regulation of these functions. We investigated the involvement of the RNA chaperones $\mathrm{Hfa}$ and ProQ in the production of the main $D$. dadantii virulence functions. Phenotypic assays on the $h f q$ and $p r o Q$ mutants showed that inactivation of $h f q$ resulted in a growth defect, a modified capacity for biofilm formation and strongly reduced motility, and in the production of degradative extracellular enzymes (proteases, cellulase, and pectate lyases). Accordingly, the $h f q$ mutant failed to cause soft rot on chicory leaves. The proQ mutant had reduced resistance to osmotic stress, reduced extracellular pectate lyase activity compared to the wild-type strain, and reduced virulence on chicory leaves. Most of the phenotypes of the $h f q$ and $p r o Q$ mutants were related to the low amounts of mRNA of the corresponding virulence factors. Complementation of the double mutant $h f q-p r o Q$ by each individual protein and cross-complementation of each chaperone suggested that they might exert their effects via partially overlapping but different sets of targets. Overall, it clearly appeared that the two Hfq and ProQ RNA chaperones are important regulators of pathogenicity in $D$. dadantii. This underscores that virulence genes are regulated post-transcriptionally by non-coding RNAs.

Keywords: Dickeya dadantii 3937, ProQ, Hfq, virulence, non-coding RNA (ncRNA)

\section{INTRODUCTION}

Dickeya dadantii is a Gram-negative phytopathogenic bacterium responsible for soft rot disease in a wide range of plant species including economically important crops (e.g., potato, chicory, sugar beet) and many ornamental plants (Ma et al., 2007). It causes important production losses (Toth et al., 2011).

Virulence mechanisms of $D$. dadantii have been extensively studied (Ma et al., 2007). The infection process is divided in two distinct phases: (i) an asymptomatic phase when the bacterium penetrates into the host and progresses through intercellular spaces without multiplying 
substantially; and (ii) a symptomatic phase associated with strongly increased bacterial fitness and multiplication (Fagard et al., 2007). Globally, the four main steps of plant infection by Dickeya are the following: (i) adherence to the plant surface and entry into the plant tissues, via wound sites or through natural openings such as stomata, (ii) colonization of the apoplastic spaces between plant cells, (iii) suppression of the host defense response, and (iv) plant cell wall degradation (through degradative extracellular enzyme production, mainly pectate lyases) resulting in the development of disease symptoms. Each of these disease stages and life-history transitions requires the correct spatio-temporal production of the different adaptive and virulence factors (including those involved in adhesion, motility, stress resistance, and plant cell wall degradation) in response to various signals (changes in cell density, variation in environmental physico-chemical parameters, and host disease reaction) (Reverchon and Nasser, 2013).

To characterize the regulation of this pathogenic process, investigations on $D$. dadantii have mostly focused on its control by DNA-binding transcription factors (Reverchon and Nasser, 2013; Leonard et al., 2017) with a few additional studies about the regulatory role of chromosome dynamics (Ouafa et al., 2012; Jiang et al., 2015; Meyer et al., 2018). Knowledge of the post-transcriptional regulation of virulence factor production by sRNAs in D. dadantii is still in its infancy.

Post-transcriptional regulation is defined as the control of gene expression at the RNA level and classically occurs through base-pairing interactions between regulatory RNAs (sRNAs) and mRNAs. This base pairing can have positive or negative effects on the stability and/or the translation of the targeted mRNA. These sRNAs can be broadly divided into two categories according to their genomic location: (i) cis-acting antisense sRNAs are transcribed from the opposite strand of their targets and act via extensive base pairing; and (ii) trans-acting sRNAs mostly originate from intergenic regions, display partial sequence complementarities with their mRNA targets and can regulate more than one target. The interactions between sRNAs and their targets are often assisted by specialized RNA-binding proteins called RNA chaperones.

A prominent bacterial RNA chaperone is the Hfq protein which contributes to regulation by trans-acting sRNAs in many bacteria (Updegrove et al., 2016). Hfq was first discovered in Escherichia coli as an essential host factor of the RNA bacteriophage Qbeta. Hfq impacts multiple steps, like changing RNA structure, bringing RNAs into proximity, neutralizing the negative charge of the two pairing RNAs, stimulating the nucleation of the first base pairs as well as facilitating the further annealing of the two RNA strands. While estimates of the number of $\mathrm{Hfq}$ vary from $\approx 20,000$ to 60,000 (Kajitani et al., 1994; Ali Azam et al., 1999), it is clear that Hfq is limiting under most conditions (Wagner, 2013).

Other proteins with possible chaperone activity have been reported recently. For example, the monomeric ProQ protein of Salmonella enterica is an RNA-binding protein that interacts with and stabilizes over 50 highly structured antisense and transacting sRNAs (Smirnov et al., 2016). The cellular concentration of ProQ was estimated to be 2,000 copies per cell (Sheidy and
Zielke, 2013). This protein was originally identified as being important for osmolyte accumulation in E. coli by increasing cellular levels of the proline transporter ProP (Milner and Wood, 1989; Kunte et al., 1999) and was later shown to possess RNA strand exchange and RNA annealing activities (Chaulk et al., 2011). Thus, ProQ was initially described as an RNA chaperone that controls ProP levels in E. coli. In Legionella pneumophila, the ProQ equivalent protein (called RocC) interacts with one trans-acting sRNA to control the expression of genes involved in natural transformation (Attaiech et al., 2016). ProQ belongs to the RNA-binding proteins of the FinO family. FinO has been studied for its role as an RNA chaperone in antisense regulation of F plasmid conjugation in E. coli (Mark Glover et al., 2015). As shown in S. enterica, ProQ seems to recognize stable RNA hairpins such as transcriptional terminators and reading the RNA structure rather than its sequence (Holmqvist et al., 2018).

While several recent studies have addressed a potential role of $\mathrm{Hfq}$ in the virulence of phytopathogenic bacteria like Agrobacterium tumefaciens (Wilms et al., 2012), Erwinia amylovora (Zeng et al., 2013), Pantoea ananatis (Shin et al., 2019), Pectobacterium carotovorum (Wang et al., 2018), and Xanthomonas campestris (Lai et al., 2018), nothing is known about the impact of $\mathrm{Hfq}$ and ProQ on $D$. dadantii virulence. Moreover, potential links between ProQ and the virulence of plant-pathogenic bacteria have never been established. To address these questions, we constructed and characterized $h f q$ and proQ mutants. Loss of Hfq or ProQ resulted in drastically reduced virulence. This phenotype was associated with the alteration of several virulence determinants including pectate lyase production, motility, and adhesion. Additionally, analyses of mutants defective in the two proteins suggested that these two RNA chaperones might exert their effects via partially overlapping but different sets of targets.

\section{MATERIALS AND METHODS}

\section{Bacterial Strains, Plasmids and Culture Conditions}

The bacterial strains, plasmids, phages and primers used in this study are described in Supplementary Tables 1-3. E. coli and D. dadantii strains were grown at 37 and $30^{\circ} \mathrm{C}$, respectively, in Lysogeny broth (LB) medium or in M63 minimal medium (Miller, 1972) supplemented with $0.1 \mathrm{mM} \mathrm{CaCl}_{2}, 0.2 \%$ (w/v) sucrose and $0.25 \%(\mathrm{w} / \mathrm{v})$ polygalacturonate (PGA, a pectin derivative from Agdia Biofords) as carbon sources. PGA induces the synthesis of pectate lyases, which are the essential virulence factors of $D$. dadantii. Sucrose has been chosen because it is one of the major sugars in the apoplast (Lohaus et al., 2001). When required, the media were supplemented with antibiotics at the following concentrations: ampicillin (Amp) $100 \mu \mathrm{g} / \mathrm{mL}$, chloramphenicol (Cm) $20 \mu \mathrm{g} / \mathrm{mL}$, kanamycin (Kan) $50 \mu \mathrm{g} / \mathrm{mL}$. The media were solidified with $1.5 \%$ (w/v) Difco agar. Liquid cultures were grown in a shaking incubator (220 r.p.m.). Bacterial growth in liquid medium was estimated by measuring turbidity at $600 \mathrm{~nm}\left(\mathrm{OD}_{600}\right)$ spectrophotometer Prim' Light Secomam to determine growth rates. 


\section{Gene Knockout and Complementation of the Hfq- and ProQ-Encoding Genes in D. dadantii}

The $h f q$ gene was inactivated by introducing a uidA-Kan cassette into the unique BsrGI restriction site present in its open reading frame. The uidA-Kan cassette (Bardonnet and Blanco, 1992) includes a promoterless uidA gene that conserves its Shine Dalgarno sequence.

To create a $\triangle$ proQ::Cm mutant, segments located 500 bp upstream and 500 bp downstream of proQ were amplified by PCR using primer pairs P1-P2 and P3-P4 (Supplementary Table 3). Primers P2 and P3 included a unique restriction site for BglII and were designed to have a short 20-bp overlap of complementary sequences. The two separate PCR fragments were attached together by overlap extension polymerase chain reaction using primers $\mathrm{P} 1$ and $\mathrm{P} 4$. The resulting $\triangle$ proQ-BglII PCR product was cloned into a pGEMT plasmid to create plasmid pGEM-T$\Delta$ proQ-BglII. The $\mathrm{Cm}$ resistance cassette from plasmid $\mathrm{pKD} 3$ (Datsenko and Wanner, 2000) was inserted into the unique BglII site of pGEM-T- $\Delta$ proQ-BglII to generate pGEM-T- $\Delta$ proQ::Cm (Supplementary Table 2).

We took care to select cassettes without transcription termination signals in order to avoid polar effects on downstream genes for both insertions. The insertions were introduced into the $D$. dadantii chromosome by marker exchange recombination between the chromosomal allele and the plasmid-borne mutated allele. The recombinants were selected after successive cultures in low phosphate medium in the presence of the suitable antibiotic because pGEMT (which is a pBR322 derivative) is very unstable in these conditions (Roeder and Collmer, 1985). Correct recombination was confirmed by PCR. Mutations were transduced into a clean D. dadantii 3937 genetic background using phage ФEC2 (Supplementary Table 1; Resibois et al., 1984).

For complementation of the $h f q$ and proQ mutations, the promoter and coding sequences of the proQ and $h f q$ genes were amplified from $D$. dadantii 3937 genomic DNA using primers P5/P6 and P7/P8, respectively (Supplementary Table 3). The forward primers (P5 and P7) included a unique restriction site for NheI, and the reverse primers (P6 and P8) included a unique restriction site for HindIII. After digestion with NheI and HindIII, each PCR fragment was ligated into pBBR1-mcs4 previously digested by NheI and HindIII to generate pBBR1$m c s 4:: h f q$ and pBBR1-mcs4::proQ, respectively (Supplementary Table 2). Correct constructions were confirmed by sequencing.

\section{Agar Plate Detection Tests for Pectate Lyase, Cellulase, Protease and Other Enzyme Assays}

Protease activity was detected on medium containing skim milk (12.5 $\left.\mathrm{g} \mathrm{L}^{-1}\right)$. Cellulase activity was detected on carboxymethylcellulose agar plates with the Congo red staining procedure (Teather and Wood, 1982). Pectate lyases were assayed on toluenized cell extracts. Pectate lyase activity was measured by recording the degradation of PGA into unsaturated products that absorb at $230 \mathrm{~nm}$ (Moran et al., 1968). Specific activity was expressed as nmol of unsaturated products liberated per min per mg of bacterial dry weight, given that an $\mathrm{OD}_{600}$ of 1 corresponded to $10^{9}$ bacteria. $\mathrm{mL}^{-1}$ and to $0.47 \mathrm{mg}$ of bacterial dry weight. $\mathrm{mL}^{-1}$.

\section{Stress Resistance Assays}

Stress resistance assays were performed as previously described (Duprey et al., 2019). Bacteria were cultured at $30^{\circ} \mathrm{C}$ in 96 -well plates using M63S (M63 + 0.2\% w/v sucrose), $\mathrm{pH} 7.0$, as minimal medium. Bacterial growth $\left(\mathrm{OD}_{600}\right)$ was monitored for $48 \mathrm{~h}$ using an Infinite ${ }^{\circledR} 200$ PRO - Tecan instrument. Resistance to osmotic stress was analyzed using M63S enriched in 0.05 to $0.5 \mathrm{M} \mathrm{NaCl}$. Resistance to oxidative stress was analyzed in the same medium by adding $\mathrm{H}_{2} \mathrm{O}_{2}$ concentrations ranging from 25 to $200 \mu \mathrm{M}$. The $\mathrm{pH}$ effect was analyzed using the same M63S medium buffered with malic acid at different $\mathrm{pH}$ values ranging from 3.7 to 7.0.

\section{Biofilm Measurements}

Biofilm formation was quantified using the microtiter plate static biofilm model. Bacteria were grown for $48 \mathrm{~h}$ at $30^{\circ} \mathrm{C}$ in 24 -well plates in M63 medium supplemented with glycerol as the carbon source. Then, the supernatant was removed, and the biofilm was washed once with $1 \mathrm{~mL}$ of M63 medium and resuspended in $1 \mathrm{~mL}$ of the same medium. The percentage of adherence was then calculated as the ratio of the number of cells in the biofilm over the total number of cells, i.e., biofilm cells over planktonic cells. The amount of planktonic cells was estimated by measuring the optical density at $600 \mathrm{~nm}$ of the supernatant and the washing buffer. The amount of cells in the biofilm was estimated by measuring the $\mathrm{OD}_{600}$ of the biofilm resuspended in M63.

\section{Motility and Chemotaxis Assays}

For the proQ mutant, motility assays were performed on semisolid LB agar plates. An overnight bacterial culture was prepared as described above, and then inoculated in the center of each of eight Petri dishes with a sterile toothpick. For motility experiments, $0.3 \%$ agar plates were used. Halo sizes were examined after incubation at $30^{\circ} \mathrm{C}$ for $24 \mathrm{~h}$. Motility indexes were calculated as the ratios of the mutant halo size over the wild type (WT) halo size.

For the $h f q$ mutant, motility assays were performed in competition (to avoid the influence of bacterial growth), as previously described (Ashby et al., 1988). Briefly, $10 \mathrm{~mL}$ of bacteria in their exponential growth phase were washed twice in sodium-free buffer and then concentrated in $3 \mathrm{~mL}$. Capillary assays were performed in competition in an equal 1:1 ratio. Suspension dilutions of chemotaxis assays were spotted onto LB agar medium supplemented when necessary, with antibiotics to select strains harboring plasmid or cassette. Different bacterial populations were thus enumerated on LB agar plates allowing the growth of both wild-type cells and $h f q:: u i d A$-Kan mutants and LB agar plates containing kanamycin allowing the growth of $h f q:: u i d A-K a n$ mutants only. Motility indexes were calculated as the ratios of the number of $h f q$ ::uidA-Kan mutants over the number of wild-type cells. The number of wild-type cells was estimated by subtracting the number of growing cells on LB agar 
plates containing kanamycin ( $h f q$ mutants) from the number of growing cells on LB agar plates containing kanamycin (wild-type and $h f q$ mutant).

\section{Virulence Assays}

Virulence assays were performed on wounded chicory leaves by depositing a drop of inoculum as previously described (Dellagi et al., 2005). Briefly, chicory leaves were wounded with a $2 \mathrm{~cm}$ incision using a sterile scalpel, inoculated with $510^{6}$ bacteria and incubated at $30^{\circ} \mathrm{C}$ in a dew chamber at $100 \%$ relative humidity. Disease severity was determined 18 and $48 \mathrm{~h}$ after inoculation by collecting and weighing the macerated tissues. The bacteria were estimated by measuring turbidity at $600 \mathrm{~nm}\left(\mathrm{OD}_{600}=1\right.$ corresponds to $10^{9}$ bacteria/ $\mathrm{mL}^{-1}$ ).

\section{Quantitative RT-PCR Analyses}

Gene expression analyses were performed using qRT-PCR. Total RNAs were extracted and purified from cultures grown to the late exponential phase $\left(\mathrm{OD}_{600}=0.8\right)$ as previously described (Maes and Messens, 1992; Hommais et al., 2008). Reverse transcription and quantitative PCR were performed using the REvertAid First Strand cDNA synthesis kit and the Maxima SYBR Green/ROX qPCR Master Mix (Thermo Scientific) with an LC480 Lightcycler (Roche). Primer specificity was verified by melting curve analysis. qPCR primers are listed in Supplementary Table 4.

\section{Data Representation and Statistical Analysis}

Boxplot representations were generated using $\mathrm{R}$ software ( $\mathrm{R}$ Core Team, 2020) and the beeswarm package (Eklund, 2016). Statistical analysis was performed using Wilcoxon MannWhitney tests, and differences were considered significant when the $P$ value $<0.05$.

\section{RESULTS}

\section{Analysis of $D$. dadantii $\mathrm{Hfq}$ and ProQ Protein Sequences and Their Genomic Contexts}

Escherichia coli and Dickeya dadantii Hfq proteins displayed 83\% identity. The highest identity level was in the $\mathrm{N}$-terminal region (amino acids 1-74), which forms the core of the protein and contains its RNA-binding sites (Link et al., 2009). Most of the amino acids involved in RNA interactions were conserved except E18, which was K18 in D. dadantii (Supplementary Figure 1). D. dadantii ProQ was $68 \%$ identical with E. coli ProQ, with also high identity in the N-terminal FinO domain of ProQ, which is the primary determinant of its RNA-binding capacity (Chaulk et al., 2011; Gonzalez et al., 2017). In particular, the regions spanning residues $1-10$ and $92-105$, shown to interact with RNA, were highly conserved (Gonzalez et al., 2017). All the residues involved in the formation of a basic patch on the protein surface (R32, R69, R80, R100, K101, K107, and R114) - an important structure for interaction with RNAs - were conserved (Supplementary Figure 1).
The $h f q$ and proQ genes are embedded in the same chromosomal context in $D$. dadantii as in other bacteria such as E. coli or S. enterica (Supplementary Figure 2). The $h f q$ gene is part of the well conserved amiB-mutL-miaA-hfq-hflXKC cluster (Tsui and Winkler, 1994), while proQ is localized between $y e b R$ and prc. Inspection of the transcriptomes of $D$. dadantii under various physiological conditions (Reverchon et al., 2021) showed that transcription of $h f q$ could be driven by (i) a promoter upstream of $m u t L$, (ii) a promoter inside $m u t L$ and upstream of $m i a A$, or (iii) two promoters inside miaA and upstream of $h f q$ (Supplementary Figure 2). Considering the expression level of mutL-miaA-hfq genes, it appears that $h f q$ was largely transcribed from the two promoters inside miaA and rarely co-transcribed with miaA. The downstream genes showed similar expression profiles and did not exhibit any promoter activity downstream of $h f q$, suggesting that they may be co-transcribed with $h f q$ in the same way as in E. coli (RegulonDB ${ }^{1}$ ). Two promoters were found upstream of the $p r o Q$ gene (one between proQ and $y e b R$ and one upstream of $y e b R$ ) (Supplementary Figure 2B). Regarding the difference in read coverage obtained from RNAseq experiments, yebR and $p r o Q$ seemed to be largely transcribed separately (Supplementary Figure 2B). On the contrary, prc and proQ had similar coverage, and no transcription start site was found between them, supporting co-transcription similarly to what is observed in E. coli (RegulonDB, see text footnote 1). The polycistronic organization and promoters for both $h f q$ and proQ were confirmed by direct RNA sequencing using the nanopore technology (R. Forquet, personal communication).

\section{Phenotypic Characterization of the $h f q$ and proQ Mutants}

We first analyzed the growth characteristics of the $h f q$ and proQ mutants. The WT, $h f q$ and proQ strains were grown in LB rich medium and in M63 minimal medium supplemented with sucrose as the sole carbon source. Sucrose was chosen because it is one of the major sugars of the apoplast (Lohaus et al., 2001). While the proQ mutant and the WT grew similarly in both media, the $h f q$ mutant exhibited delayed growth. However, in rich medium both the WT strain and $h f q$ mutant reached the same optical density after being grown for $26 \mathrm{~h}$ (Figure 1A). In minimal medium with sucrose as the sole carbon source, the $h f q$ mutant grew much more slowly than the WT, and reached the stationary phase at a lower optical density (Figure 1B). The growth defect of the $h f q$ mutant was fully restored by complementation with plasmid pBBR-mcs4::hfq (Figure 1), indicating that the $h f q:$ :uidA-Kan insertion had no polar effects on downstream $h f l X K C$ genes. In contrast, transformation of the proQ mutant and WT strains with the pBBR-mcs4::proQ plasmid expressing proQ led to a lower growth rate, especially in minimal medium (Figure 1D). The two strains grew similarly in the absence of the pBBR-mcs4::proQ plasmid. This suggests that slight ProQ overexpression compromises growth irrespective of the genetic background. These data demonstrate that $h f q$ mutation retards cellular growth, while proQ mutation does not. The effect was more pronounced in minimal medium compared to rich

\footnotetext{
${ }^{1}$ http://regulondb.ccg.unam.mx/
} 
A

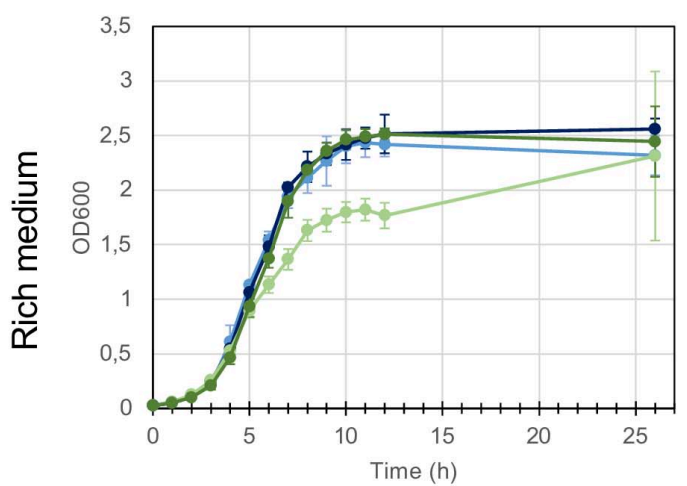

B

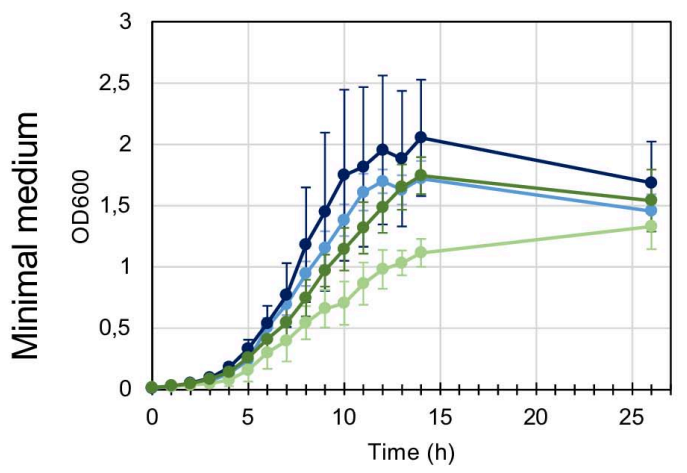

C

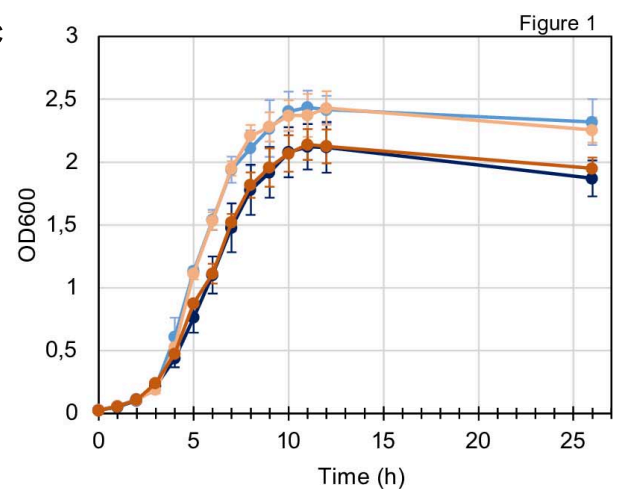

D

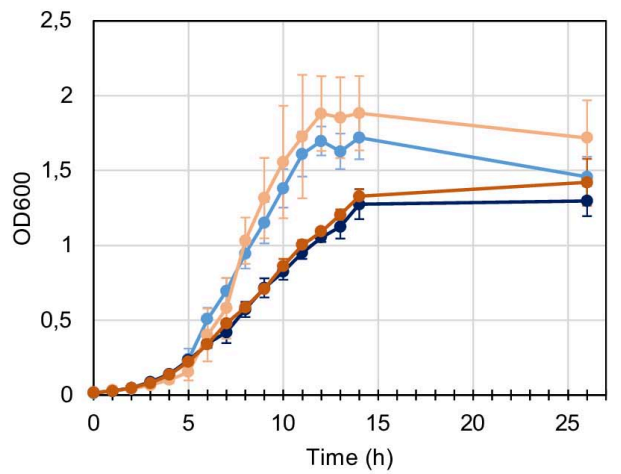

\begin{tabular}{|c|c|c|c|c|c|c|c|c|c|}
\cline { 2 - 9 } \multicolumn{1}{c|}{} & - & - & - & - & & - & - & - & - \\
\hline Strain & $\Delta h f q$ & $\Delta h f q$ & WT & WT & & $\Delta p r o Q$ & $\Delta p r o Q$ & WT & WT \\
\cline { 1 - 7 } Plasmid & Control & $h f q$ & Control & $h f q$ & & Control & proQ & Control & proQ \\
\hline
\end{tabular}

FIGURE 1 | Growth of the wild type, mutant and complemented strains in LB rich medium (A,C) and M63 minimal medium supplemented with sucrose (B,D). Overnight bacterial precultures were diluted to an $\mathrm{OD}_{600}$ of 0.03 in the same growth medium. $\mathrm{OD}_{600}$ measurements of the culture were made at regular intervals to determine growth rates. The experiment was repeated three times. The graph shows curves from one representative experiment. Error bars represent deviation of biological replicates.

medium, suggesting that Hfq plays a more important role in the ability of $D$. dadantii to grow under conditions of nutrient limitation. A similar growth defect of $h f q$ mutants has been observed in other bacteria such as P. carotovorum (Wang et al., 2018), A. tumefaciens (Wilms et al., 2012), X. campestris (Lai et al., 2018), P. ananatis (Shin et al., 2019) or E. amylovora (Zeng et al., 2013).

Dickeya encounter various stresses during their pathogenic growth, so we assessed the stress resistance of the $h f q$ and proQ mutants (Supplementary Figure 3). They both showed behaviors similar to the WT strain regarding $\mathrm{pH}$ and $\mathrm{H}_{2} \mathrm{O}_{2}$ stress resistance, but displayed a higher sensitivity to osmotic stress than the WT strain did. The $h f q$ mutant displayed a $50 \%$ growth rate reduction on $0.4 \mathrm{M} \mathrm{NaCl}$, while the WT strain was only slightly affected (20\% growth rate reduction). This effect was even more pronounced at $0.5 \mathrm{M} \mathrm{NaCl}$, with a growth rate reduction of $90 \%$ for $h f q$ compared to $60 \%$ for the WT. The proQ mutant did not grow at $0.3 \mathrm{M} \mathrm{NaCl}$ and at higher $\mathrm{NaCl}$ concentrations (Supplementary Figure 3). Complementation experiments revealed that expression of $h f q$ or proQ from an episome (plasmid pBBR-mcs4::hfq and pBBR1mcs4::proQ) fully restored the osmotic resistance of the two mutants to the WT level (Supplementary Figure 3). We inferred that the two chaperones are involved in providing resistance to osmotic stress. Overall, this result is consistent but not identical with previous studies showing that Hfq and ProQ contribute to stress tolerance, including nutrient deprivation, osmotic stress and oxidative stress in Salmonella and E. coli (Chaulk et al., 2011; Smirnov et al., 2017).

\section{Hfq and ProQ Are Required for Full Virulence of Dickeya dadantii}

The virulence of the $h f q$ and proQ mutants was tested on chicory leaves. The $h f q$ mutant was severely impaired in virulence, and soft rot symptoms were drastically reduced (Figure 2A). Disease symptoms were observed following inoculation with the proQ mutant and the WT strain, but they were less severe in the proQ background. Quantitative results obtained by measuring the weight of macerated tissues showed a significant difference between the disease symptoms induced by each strain ( $p$ value $=1.5 \mathrm{e}-3)$ (Figures $2 \mathrm{~B}, \mathbf{C})$. As observed previously, the virulence defect of the $h f q$ mutant was more severe than that of the proQ mutant, in as far as the $h f q$ mutant did not exhibit 
A

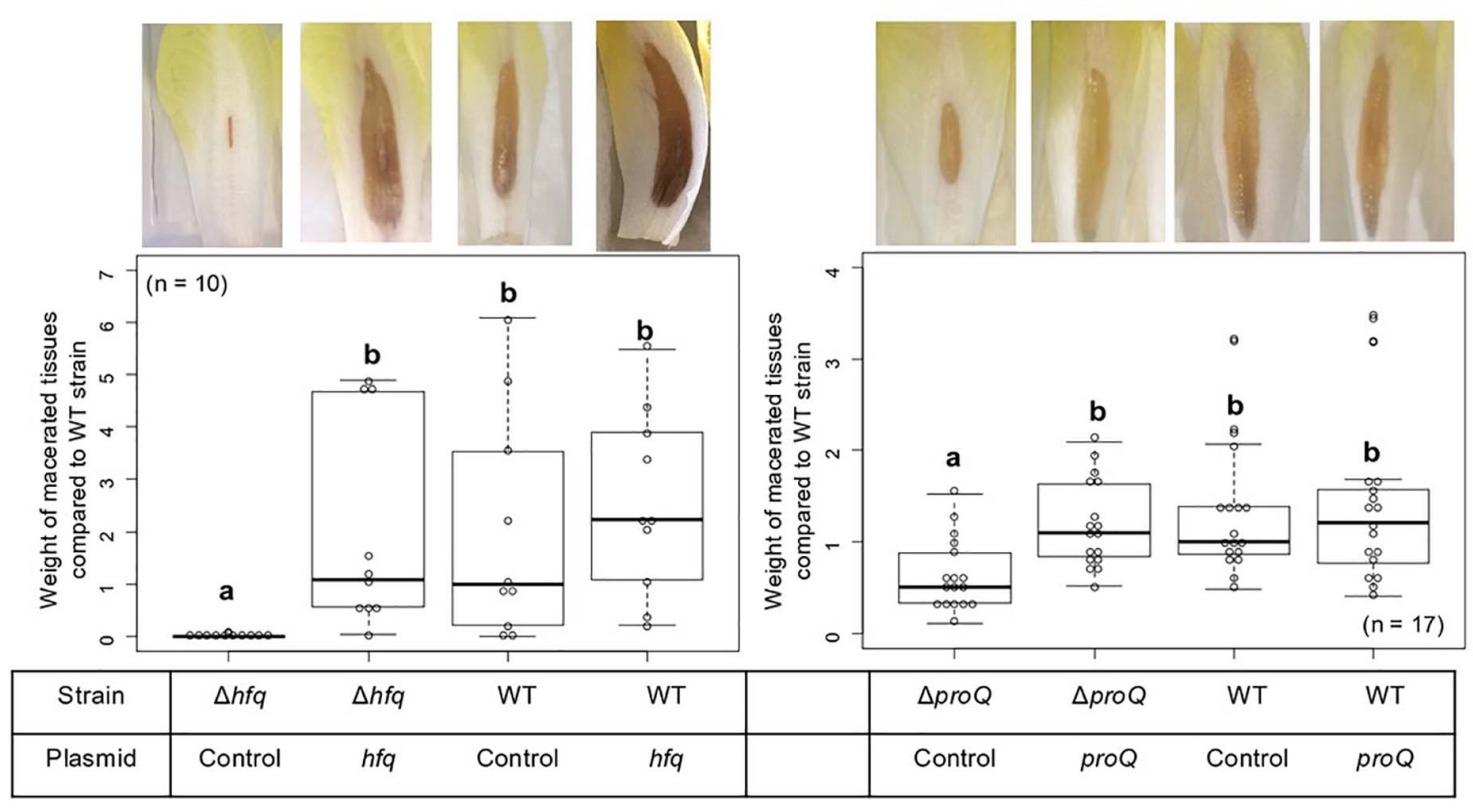

FIGURE 2 | Impact of $\mathrm{Hfq}$ and ProQ on D. dadantii virulence. Representative examples of symptoms induced by the wild type and mutant strains and weights of macerated tissues following infection by the $h f q(\mathbf{A})$ and $p r o Q$ mutants $(\mathbf{B})$, the wild type strain and the respective complemented strains. Data were normalized based on the weights of macerated tissues from the wild-type strain. Chicory leaf assays were performed as described in the Materials and methods section with an incubation time of $18 \mathrm{~h}$, and weights of macerated tissues were measured. The experiments were repeated three times with ten leaves tested in each replicate. Non-capital letters $a$ and $b$ are presented above the boxplots. Groups with the same letter are not detectably different (are in the same set) and groups that are detectably different get different letters (different sets). Note that if the groups have the same letter, this does not mean they are the same, just that there is no evidence of a difference for that pair $(P<0.05$, Wilcoxon Mann-Whitney test).

any macerated tissue $(p$-value $=5.7 \mathrm{e}-4)$. Consequently, we did not weigh any macerated tissue in the $h f q$ mutant. The soft rot symptoms caused by the $h f q$ and $p r o Q$ mutants did not increase over longer incubation times $(48 \mathrm{~h})$. The lower virulence of $h f q$ and proQ was therefore not solely related to retarded cellular growth. Complementation experiments revealed that expression of $h f q$ from an episome (plasmid pBBR-mcs4::hfq) fully restored the impaired virulence of the $h f q$ mutant (Figure 2B). Likewise, expression of proQ from an episome (plasmid pBBR-mcs4::proQ) restored the impaired virulence of the proQ mutant (Figure 2B).

Thus, the $h f q$ and $p r o Q$ genes are required for efficient pathogenic growth since both mutants were clearly impaired in initiating maceration and inducing soft rot symptoms, albeit to different extents.

\section{Production of Late Virulence Factors, Pectate Lyase, Protease and Cellulase, Is Abolished in the hfq Mutant and Reduced in the proQ Mutant}

Dickeya dadantii is known to use several essential virulence factors that collectively contribute to its ability to cause disease. These factors include production of cell-wall-degrading enzymes like pectate lyases, proteases and cellulase, which are responsible for soft rot symptoms. To clarify whether Hfq and ProQ have any influence on the production of key virulence factors, we compared enzyme activity in $h f q$ and proQ mutant extracts with WT strain extracts (Figure 3A). Pectate lyase activity was abolished in the $h f q$ mutant ( $p$-value $=2.4 \mathrm{e}-7)$. This defect in pectate lyase activity was not a consequence of the growth defect of the $h f q$ mutant since activities were normalized to cell density. Also, the levels of pectate lyase activity were significantly reduced in the proQ mutant compared to the WT $(p$-value $=2.0 \mathrm{e}-9)($ Figure 3A)$)$. Reduced cellulase and protease activities were also observed on carboxymethylcellulose and skim milk agar plates for each mutant (Figure 3B). Complementation experiments showed that the impaired production of cell-walldegrading enzymes was restored in $h f q$ and proQ mutant cells transformed with the pBBR-mcs4::hfq and pBBR-mcs4::proQ plasmids, respectively (Figure 3 ). Therefore, the impaired pathogenicity of $D$. dadantii due to $h f q$ and $p r o Q$ mutations is linked with reduced production of late virulence factors in these mutant strains.

\section{Early Virulence Determinants Such as Biofilm Production and Motility Are Also Impaired in the $h f q$ and $p r o Q$ Mutants}

At the initial stage of infection, $D$. dadantii must adhere to the plant surface and enter into the apoplast. $D$. dadantii produces cellulose fibrils, which enable it to develop aggregates on the plant surface (Jahn et al., 2011; Prigent-Combaret et al., 2012). These 
A

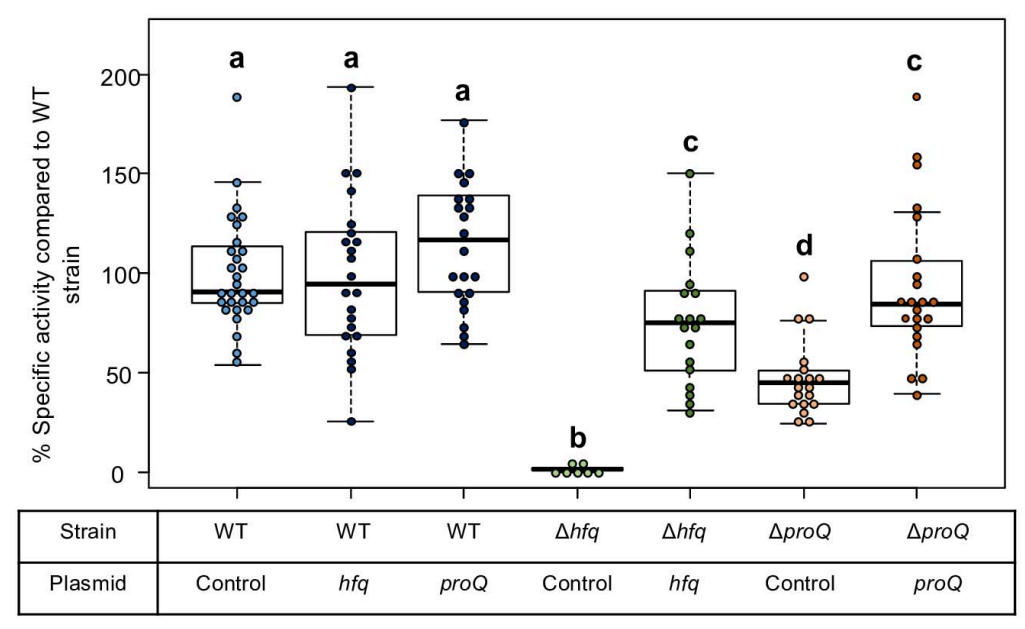

B

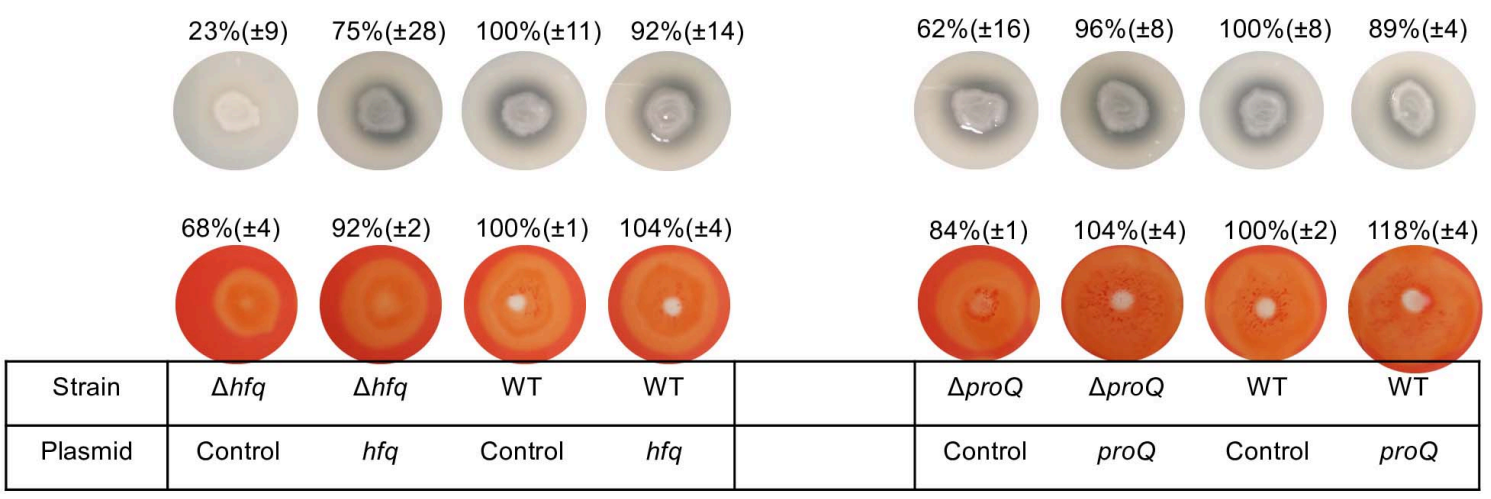

FIGURE 3 | Impact of Hfq and ProQ on cell-wall-degrading enzymes. (A) Pectate lyase activity in the wild type, mutant and complemented strains, expressed as percent of wild type strain specific activity. Experiments were repeated at least three times. Non-capital letters a, b, c, and d are presented above the boxplots. Groups with the same letter are not detectably different (are in the same set) and groups that are detectably different get different letters (different sets). Note that if the groups have the same letter, this does not mean they are the same, just that there is no evidence of a difference for that pair $(P<0.05$, Wilcoxon Mann-Whitney test). (B) Protease production on medium containing skim milk, and cellulase production on carboxymethylcellulose agar plate with Congo red staining in the $h f q$ and proQ mutants, the complemented strains and the wild type strain.

aggregates are embedded in an extracellular polymeric substance (EPS) that maintains a hydrated surface around the bacteria and thus helps them to survive under conditions of desiccation (Condemine et al., 1999). Motility and chemotaxis are essential for $D$. dadantii when searching for favorable sites to enter into the plant apoplast. Therefore, we evaluated the consequences of the $h f q$ or proQ mutations on motility and biofilm formation. The ability of the $h f q$ and $p r o Q$ mutants to swim was analyzed using capillary and soft agar assays, respectively. Incubation time during the capillary assays was short, so that we were able to overlook the impact of the growth defect between the $h f q$ mutant and the WT strain. Soft agar assays were performed to test the motility of the proQ mutant, since similar growth rates were obtained for the proQ mutant and the WT strain. A motility index was calculated for both experiments (Figure 4A). It was equal to the motility of the mutant strain (number of cells in the capillary or size of the halo) divided by that of the WT strain. Both $h f q$ and proQ showed reduced motility compared to the WT ( -38 and $-22 \%$, respectively) and strains complemented with the respective inactivated gene expressed from an episome restored the ability to swim (90 and 98\%, respectively). This reduced cell motility is in agreement with the behavior of $h f q$ mutants of most pathogenic bacteria (Chao and Vogel, 2010; Vogel and Luisi, 2011; Sobrero and Valverde, 2012; Wagner, 2013; Updegrove et al., 2016).

Flagellar motility negatively affects biofilm formation. Consequently, we monitored the consequences of the $h f q$ or proQ mutations on the attachment of $D$. dadantii to the plastic coating of the microtiter plate well. From a metabolic point of view, biofilm formation reflects the trade-off between motility and exopolysaccharide (EPS) production. This trade-off was clearly unbalanced in favor of EPS production in the $h f q$ mutant $(p$-value $=7.4 \mathrm{e}-7)$ and less severely so in the proQ mutant $(p$ value $=3.8 \mathrm{e}-2)($ Figures $4 \mathbf{B}, \mathbf{C})$. Complementation experiments demonstrated that $h f q$ expressed from an episome did not significantly reduce the increased biofilm forming capacity of the $h f q$ mutant (Figure 4B). In contrast, overexpression of proQ from the episome slightly decreased the biofilm formation capacity of 


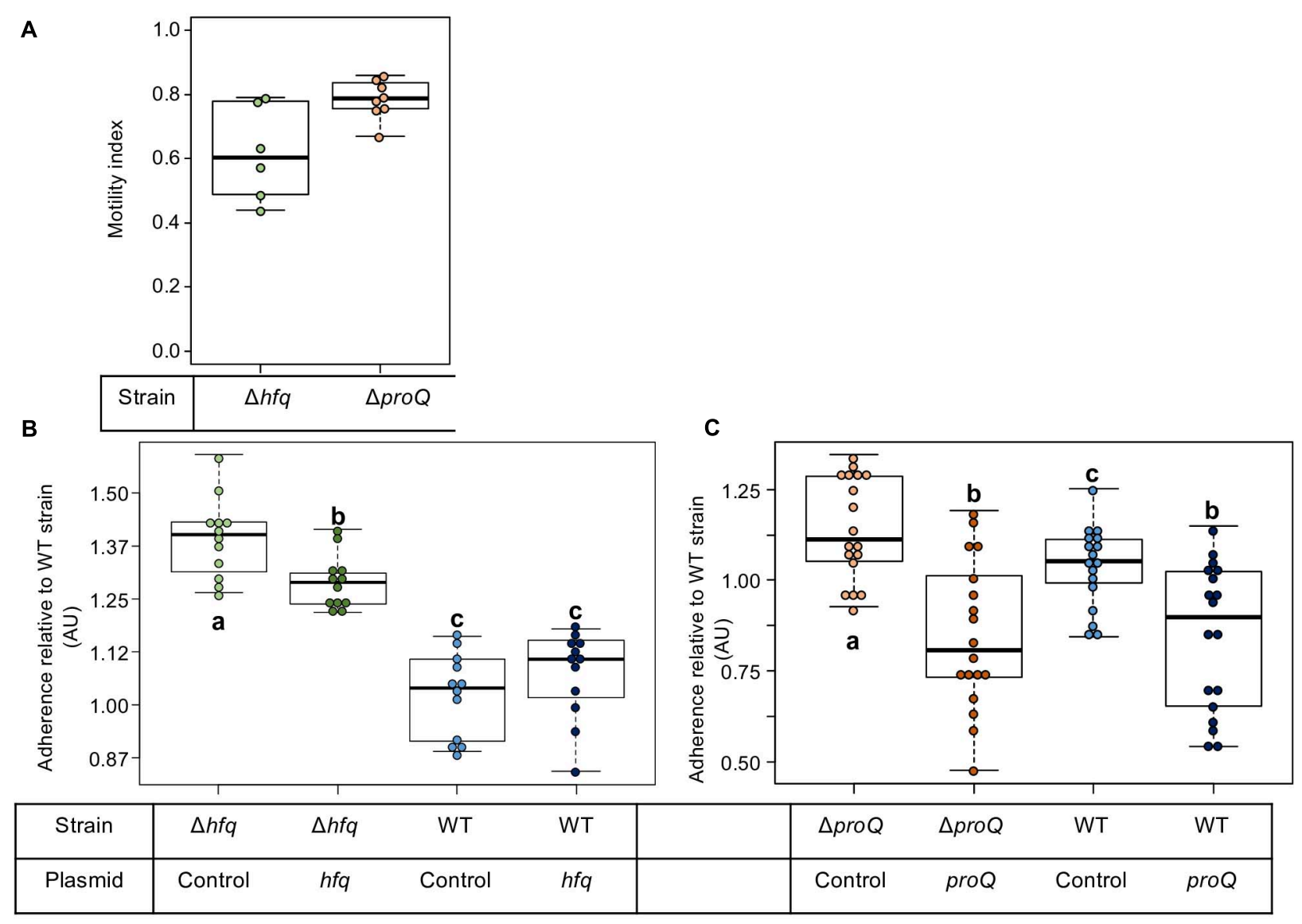

FIGURE 4 | Impact of Hfq and ProQ on motility and biofilm formation. (A) Motility indexes of the hfq and proQ mutants. Motility experiments were performed in capillary assays for the hfq mutant and in soft agar plates for the proQ mutant. The motility index was equal to the motility results of the mutant strain (number of cells in the capillary or halo size) divided by the results of the WT strain. (B,C) Impact of the hfq and proQ mutations on biofilm formation. Assays were carried out in multi-well plates. Data were normalized relative to the adherence of the wild-type strain. The effect of heterologous complementation is also showed. Quantification of the cells present in the aggregates and in the planktonic fractions for the different strains. Experiments were repeated at least three times. Non-capital letters a, b, and $c$ are presented above the boxplots. Groups with the same letter are not detectably different (are in the same set) and groups that are detectably different get different letters (different sets). Note that if the groups have the same letter, this does not mean they are the same, just that there is no evidence of a difference for that pair $(P<0.05$, Wilcoxon Mann-Whitney test).

the proQ mutant and WT strain compared to the proQ mutant and to the WT strain without complementation (Figure 4C). These data suggest that the two RNA chaperones play different roles in $D$. dadantii biofilm formation.

\section{Transcripts of Late Virulence Factors and Early Virulence Determinants Are Impaired in the $h f q$ and proQ Mutants}

Hfq and ProQ act post-transcriptionally, so we evaluated the mRNA amounts of various virulence genes in the $h f q$ and proQ mutants by qRT-PCR. For genes mostly involved in the early stage of infection, we selected $f l i C$ which encodes flagellin, $r h l A$ whose product is involved in the synthesis of a biosurfactant for swarming motility, and $b c s A$ which encodes a protein involved in the production of cellulose fibrils important for adherence. Concerning late virulence genes, we retained pelD and pelE that encode pectate lyases, prtB and prtC that encode metalloproteases, celZ that encodes a cellulase, outC that encodes a compound of the type II secretion system which secretes pectinases and cellulase, $k d g K$ that encodes the KDG kinase involved in the catabolism of polygalacturonate, and $h r p N$ that encodes harpin which elicits the hypersensitive response. In line with the observed phenotypes, the RNA amounts of most genes were reduced in both mutants, much more drastically so in the $h f q$ mutant than in the proQ mutant (Figure 5). The greater adherence of the $h f q$ mutant was also correlated with the higher $b c s A$ RNA amounts compared to the WT (increased by three-fold). However, celZ RNA amounts were similar in the $h f q$ mutant and in the WT. Therefore, the reduced cellulase activity was not dependent on the celZ RNA amount but it could be partially due to reduced cellulase secretion because the outC RNA amount was low in the $h f q$ mutant (decreased by $70 \%$ ), or to decreased CelZ translation. In the proQ mutant, the amount of celZ and outC transcripts were slightly reduced (around 40\%). Taken together, these results indicate that most of the observed 


\section{A}
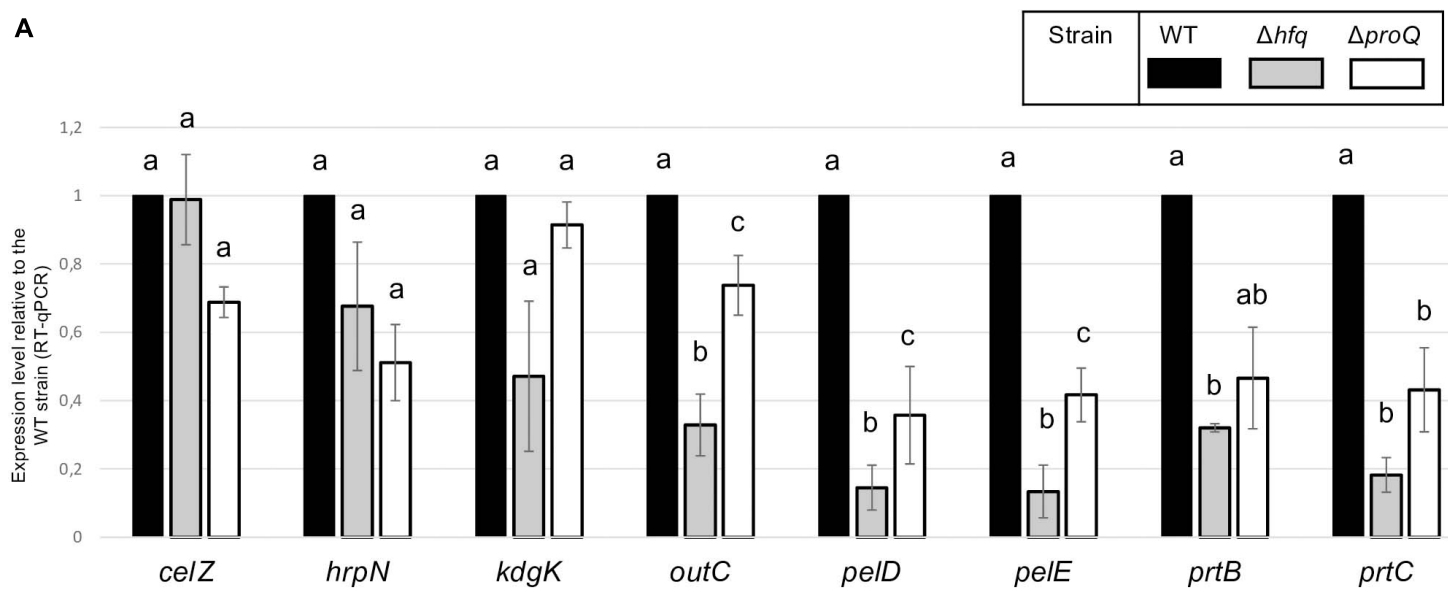

B

C
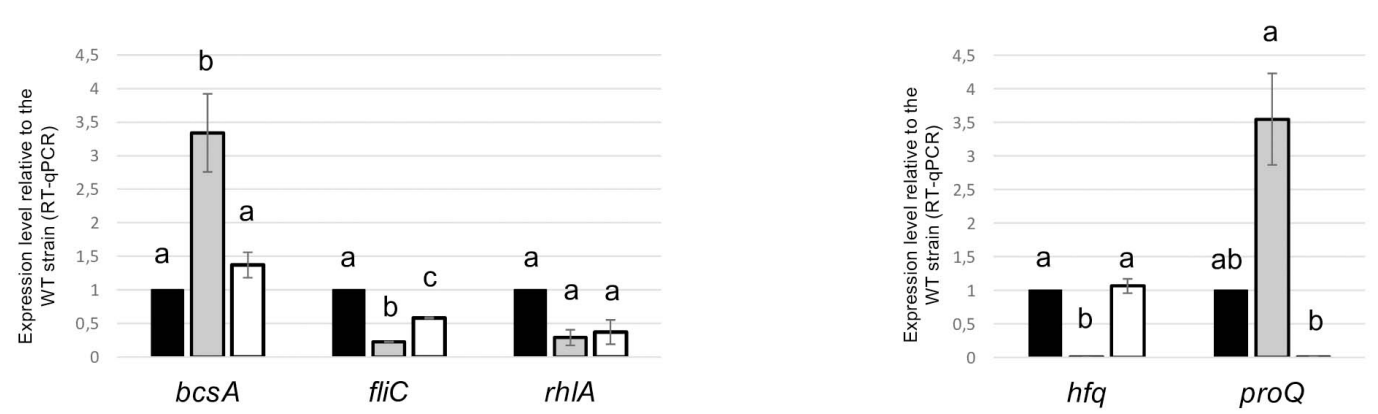

FIGURE 5 | RNA amounts in the $h f q$ and proQ mutant strains. Gene expression levels relative to the WT strain were evaluated in the two mutants by RT-qPCR. (A) Genes encoding late virulence factors or associated with late virulence factors; (B) Genes encoding early virulence factors such as adherence and motility factors; (C) Expression levels of $h f q$ and $p r o Q$ were measured in the different mutants. Non-capital letters a, b, and c are presented above the histograms. Groups with the same letter are not detectably different (are in the same set) and groups that are detectably different get different letters (different sets). Groups can have more than one letter to reflect "overlap" between the sets of groups. Note that if the groups have the same letter, this does not mean they are the same, just that there is no evidence of a difference for that pair $(P<0.05, t$-test).

phenotypes were correlated to a decrease in the mRNA amounts from virulence genes.

\section{The Effects of RNA Chaperones on Virulence Partially Overlap}

The absence of Hfq or ProQ impaired virulence and modified the production of similar virulence factors. Consequently, we evaluated the behavior of a mutant inactivated for both $h f q$ and $p r o Q$ and assessed whether $h f q$ and proQ could restore virulence in the double mutant. The virulence of the $h f q$ proQ double mutant and mutant complemented by either $h f q$ or proQ was tested on chicory leaves. The mutants were asymptomatic whatever the complementation $24 \mathrm{~h}$ post-infection, except the mutant proQ, that caused reduced soft rot symptoms as noticed earlier (Figure 2). However, $48 \mathrm{~h}$ post-infection, the proQ gene inserted in the $h f q$ proQ mutant produced a weight of macerated tissues similar to the weight observed with the $h f q$ mutant, whereas $h f q$ complementation of the double mutant only slightly restored soft rot symptoms (Figure 6). Complementation by proQ did not restored virulence while complementation by $h f q$ partially restored symptom.

Late and early virulence factors were also impaired in the double mutant, as expected. Compared to the $h f q$ mutant, the double mutant showed a similar, perhaps higher reduction of protease, cellulase and pectinase activities (Figure 7A). Motility was also reduced, and adherence was increased compared to the WT (Figures 8A,C). In line with these phenotypes, the expression levels of the corresponding genes were modified: prtC, pelD and fliC RNA amounts decreased by at least five folds in the double mutant, and $h r p N$, celZ and outC RNA amounts decreased by about two folds (Figures 7B, 8 and Supplementary Figure 4). Overall, the expression levels of outC, pelD, bcs A, and $f l i C$ were similar in the double mutant and in the $h f q$ mutant, whereas the expression levels of prtC celZ and $h r p N$ decreased more than in the $h f q$ mutant (Figures 7B, 8B and Supplementary Figure 4).

The protease, pectinase and motility phenotypes were restored by complementation with Hfq. Accordingly, prtC, pelD, and fliC RNA amounts increased significantly in the double mutant strain complemented by Hfq (Figures 7B, 8B). However, the cellulase phenotype was not complemented by the addition of $\mathrm{Hfq}$, even if the expression level of celZ was restored to a 


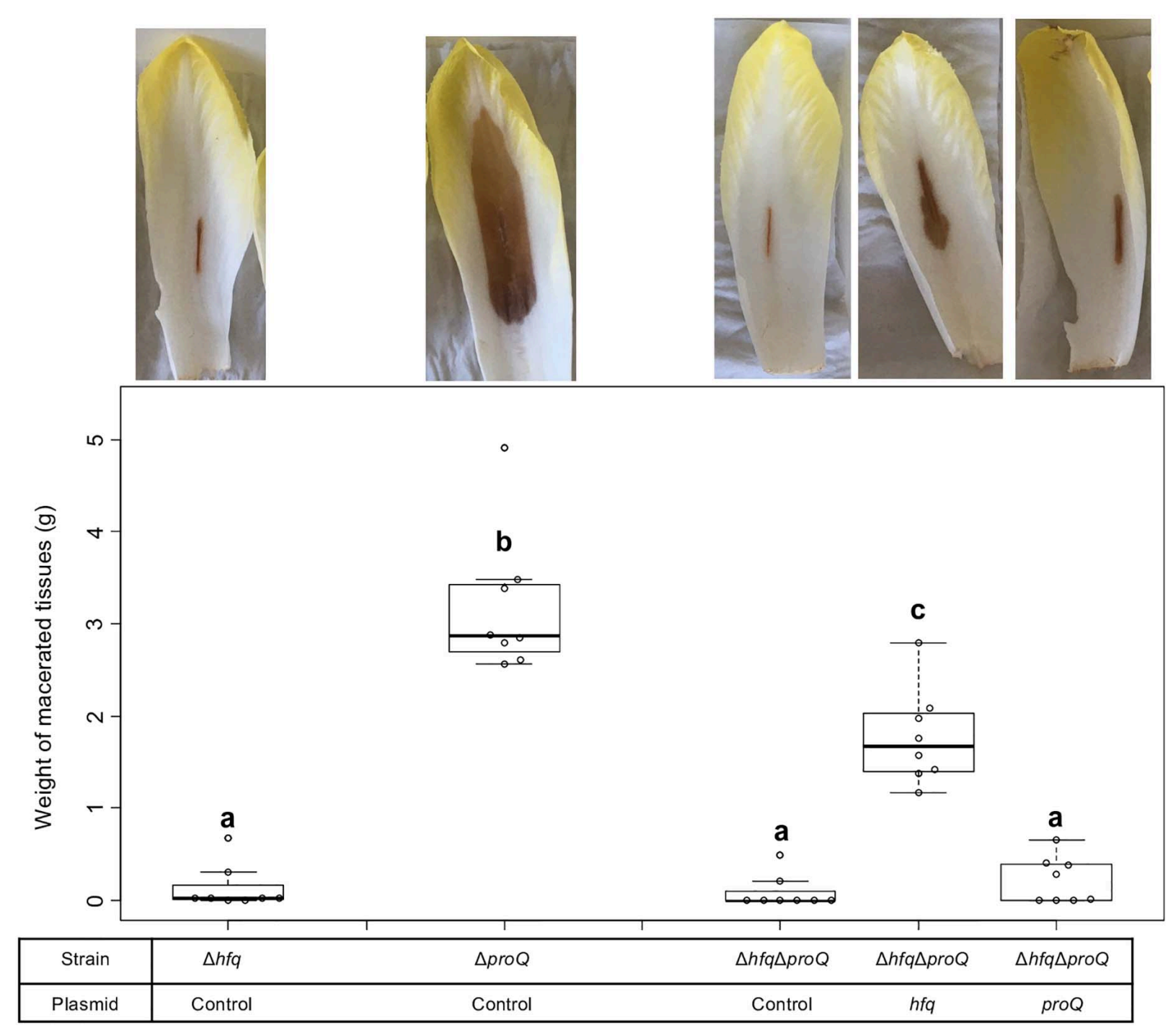

FIGURE 6 |D. dadantii virulence assays $48 \mathrm{~h}$ post-infection. Virulence was evaluated on the single mutants, the double mutant, and the double mutant complemented by Hfq or ProQ. Chicory leaf assays were performed as described in the "Materials and Methods" section with an incubation time of $48 \mathrm{~h}$. Representative examples of symptoms induced were shown and the weights of macerated tissues were measured. Experiments were repeated three times with at least seven leaves tested in each replicate. Non-capital letters a, b, and c are presented above the boxplots. Groups with the same letter are not detectably different (are in the same set) and groups that are detectably different get different letters (different sets). Note that if the groups have the same letter, this does not mean they are the same, just that there is no evidence of a difference for that pair $(P<0.05$, Wilcoxon Mann-Whitney test).

level similar to those measured in the WT or the $h f q$ mutant (Figure 7). The adherence phenotype and the expression level of $b c s A$ were not complemented by an $h f q$ gene expressed from a plasmid (Figure 8). ProQ complementation restored protease, cellulase and pectinase activities and adherence, but not motility. In accordance, the expression level of $\mathrm{fliC}$ was similar to the levels in the double mutant (Figure 8B), but the expression levels of $b c s A, \operatorname{prtC}, c e l Z$, and $h r p N$ increased in the complemented strain compared to the non-complemented double mutant (Figures 7, 8 and Supplementary Figure 4). Interestingly, the expression levels of genes outC and pelD were unexpectedly similar to those observed in the double mutant although phenotypes were restored.
We measured the expression levels of $h f q$ and proQ in the different mutants. As expected, $h f q$ and $p r o Q$ expression was not detected in the respective mutant strains or in the double mutant, but a three-fold increase was observed for the gene expressed from the plasmid. proQ expression level increased in the strains defective in $\mathrm{Hfq}$ production, i.e., 3.5 fold in the single $h f q$ mutant and around 12 fold in the double mutant complemented by proQ. These results can be explained by an additive effect of the $h f q$ mutation and of proQ overexpression from the plasmid (Figure 1 and Supplementary Figure 4).

Overall, virulence assays, phenotypes and expression level measurements suggest that the two RNA chaperones Hfq and 
A
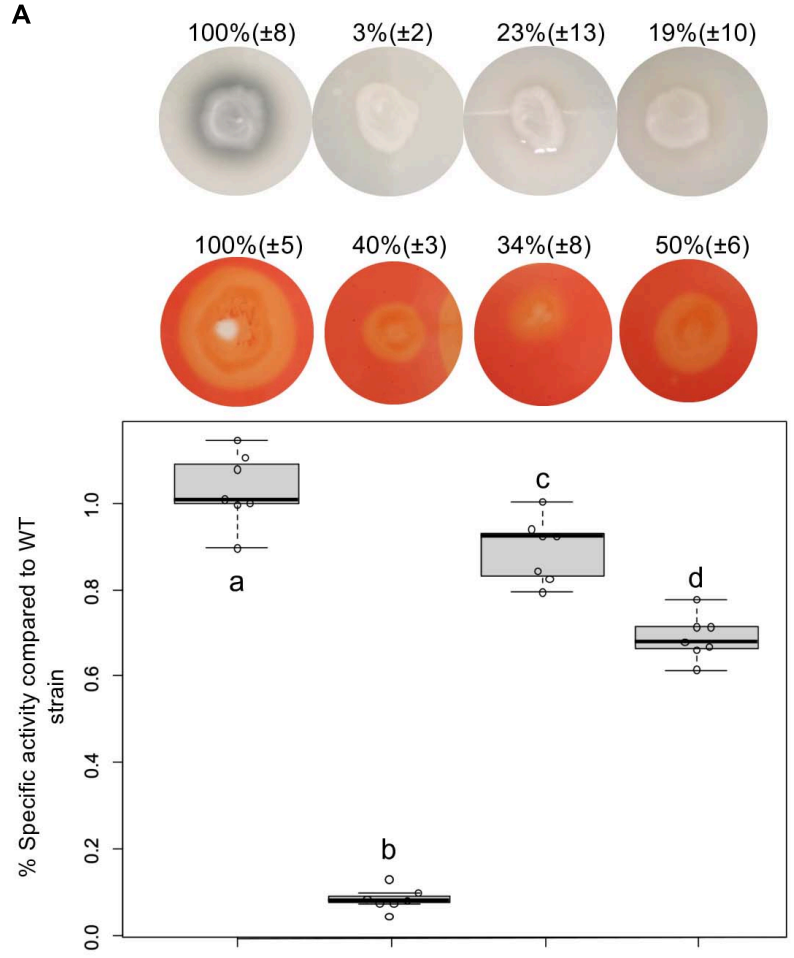

\begin{tabular}{|c|cccc|}
\hline Strain & WT & $\Delta h f q \Delta p r o Q$ & $\Delta h f q \Delta p r o Q$ & $\Delta h f q \Delta p r o Q$ \\
\hline Plasmid & Control & Control & $h f q$ & $p r o Q$ \\
\hline
\end{tabular}

B

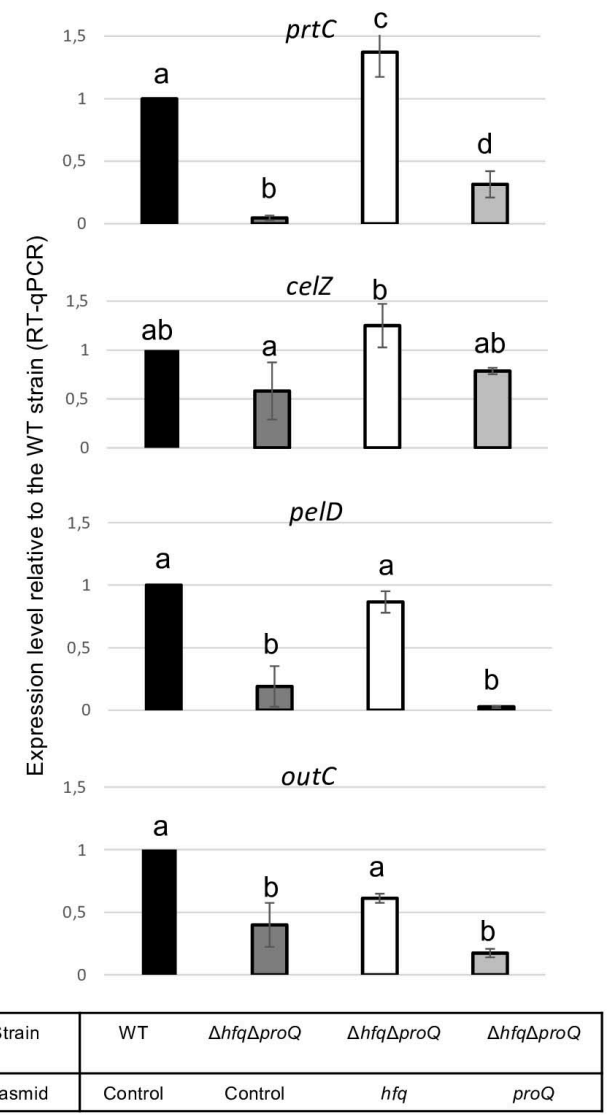

FIGURE 7 | Impact of the double mutant on late virulence factors. (A) Protease production on medium containing skim milk, cellulase production on carboxymethylcellulose agar plates with Congo red staining, and pectate lyase activity expressed as percent of wild type strain specific activity were evaluated in the double mutant and in the double mutant complemented by Hfq or ProQ. Experiments were repeated at least three times. Non-capital letters a, b, c, and d are presented above the boxplots and histograms. Groups with the same letter are not detectably different (are in the same set) and groups that are detectably different get different letters (different sets). Groups can have more than one letter to reflect "overlap" between the sets of groups. Note that if the groups have the same letter, this does not mean they are the same, just that there is no evidence of a difference for that pair $(P<0.05$, Wilcoxon Mann-Whitney test). (B) expression levels of prtC, celZ, pelD, and outC measured by RT-qPCR in the double mutant and double mutant complemented by Hfq or ProQ. Expression levels were compared with those measured in the WT strain.

ProQ exert their effects via partially overlapping but different sets of targets (Figure 9).

\section{DISCUSSION}

We investigated the influence of the two RNA chaperones Hfq and ProQ on the virulence of the bacterial plant pathogen D. dadantii. Inactivation of the genes encoding these two chaperones led to lower production of cell-degrading enzymes acting as major virulence factors during $D$. dadantii pathogenic growth, and accordingly lower pathogenicity. Furthermore, both mutations altered osmotic stress tolerance and cell motility. However, the same mutations elicited different effects on cell growth and biofilm formation. Phenotypes were mostly correlated with altered expression of genes encoding virulence factors ( $h r p N$, outC, pelD, pelE prtC, prtB), motility components ( $f l i C$ and $r h l A$ ) and adherence components (bcsA), except celZ expression in the $h f q$ mutant (Figure 9). Expression levels generally decreased less following inactivation of proQ than following inactivation of $h f q$, but both RNA chaperones affected similar virulence factors. So far, the involvement of ProQ in virulence has been only reported in Salmonella where it regulates motility directly by downregulating fliC mRNA and represses or activates the expression of virulence genes (genes localized in SPI and SPII, respectively). Accordingly, infection by a Salmonella proQ mutant resulted in a decreased invasion rate in eukaryotic cells (Westermann et al., 2019). The present study reports for the first time the involvement of ProQ in the virulence of a plant-pathogenic bacterium. The expression level of $p r o Q$ does not seem to be significantly modified during the infection (Pédron et al., 2018). In D. dadantii, major virulence genes (pel, prt and cel) were repressed by ProQ, but contrary to what has been observed in Salmonella, the amount of fliC mRNA decreased in the proQ mutant. Differences in proQ mutant behavior according to species were also highlighted by comparing mutant strains in E. coli and $D$. dadantii: the proQ mutant displayed impaired biofilm 
A

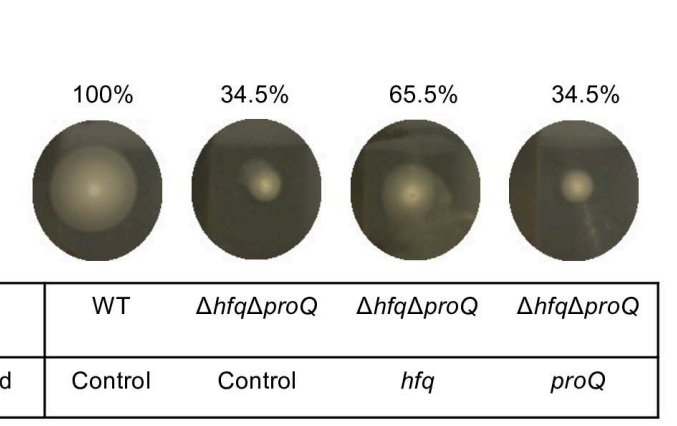

B

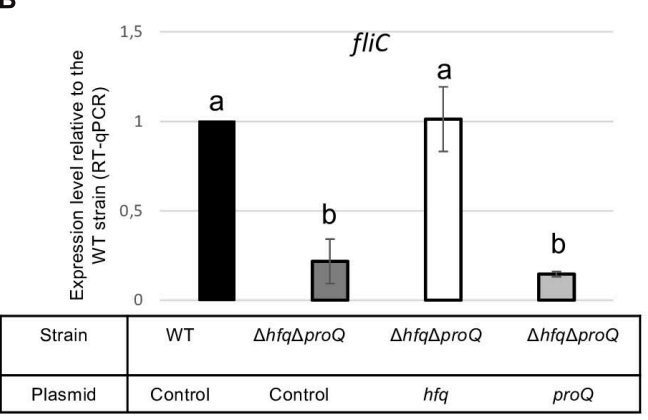

Motility is expressed as a percentage of the WT value above each Petri dish

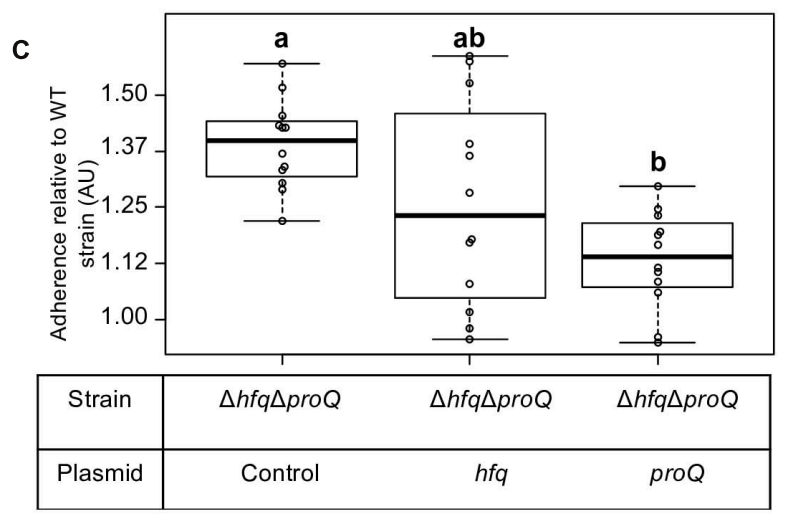

D

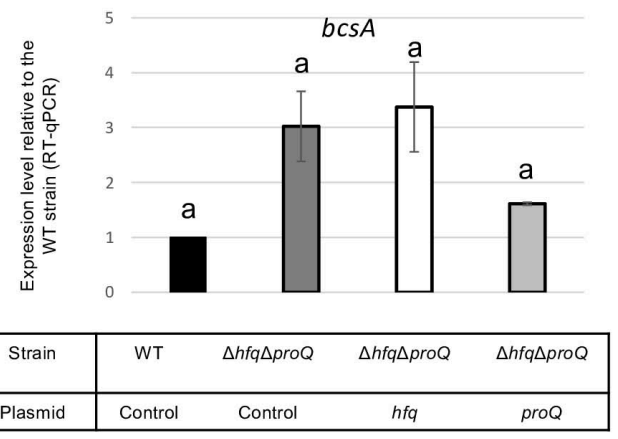

FIGURE 8 | Impact of the double mutant on early virulence factors. Phenotypes and expression levels were analyzed in the double mutant strain and the double mutant strain complemented by Hfq or ProQ. (A) Motility was evaluated on semi-solid LB agar plates; (B,D) Expression levels of genes were measured by RT-qPCR and compared with the wild type; (C) Adherence was evaluated and compared with the wild-type strain. Experiments were repeated at least three times. Non-capital letters a, b, c, and d are presented above the boxplots and histograms. Groups with the same letter are not detectably different (are in the same set) and groups that are detectably different get different letters (different sets). Groups can have more than one letter to reflect "overlap" between the sets of groups. Note that if the groups have the same letter, this does not mean they are the same, just that there is no evidence of a difference for that pair $(P<0.05$, Wilcoxon Mann-Whitney test).

formation in E. coli, whereas it displayed increased adherence in D. dadantii (Sheidy and Zielke, 2013). Overall, this illustrates the species specificities of the ProQ regulatory networks, as previously described (Attaiech et al., 2016; Smirnov et al., 2016; Holmqvist et al., 2018; Westermann et al., 2019). Specificities could be a consequence of a rather distinct sRNA landscape produced by these bacterial species, where only small numbers of sRNA homologs overlap (Leonard et al., 2019). In contrast to ProQ, Hfq proteins have already been reported to significantly reduce virulence in several plant-pathogenic bacteria like A. tumefaciens, E. amylovora, $P$. ananatis, $X$. campestris, and $P$. carotovorum. However, the role of $\mathrm{Hfq}$ still remains only partially understood (Wilms et al., 2012; Zeng et al., 2013; Zeng and Sundin, 2014; Lai et al., 2018; Wang et al., 2018; Shin et al., 2019). Additionally, D. dadantii strain defective of $h f q$ has been shown to present a decreased fitness in planta (Royet et al., 2019). The phenotypes of the $D$. dadantii $h f q$ mutant are similar to those of the $P$. carotovorum $h f q$ mutant: $h f q$-defective strains present a decreased growth rate, low cellulase, protease and pectinase production, and altered biofilm formation and motility. Hfq should regulate directly or indirectly these functions post-transcriptionally using sRNAs. In $D$. dadantii, a recent study highlighted a feed-forward signaling circuit involving $\mathrm{Hfq}$ protein which post-transcriptionally regulates RsmB involved in the downregulation of cell-degrading enzymes and type 3 secretion system (Yuan et al., 2019).

One interesting feature highlighted by this study is the interplay between the two RNA chaperones. The mitigated virulence of the double mutant was only slightly complemented by Hfq or ProQ, so we evaluated the ability of Hfq and ProQ to cross-complement each other regarding mitigation of virulence. ProQ partially complemented the $h f q$ mutant, whereas episomal $h f q$ did not complement the $p r o Q$ mutant (Supplementary Figure 5). Overall, these results indicate that these two RNA chaperones might exert their effects via partially overlapping but different sets of targets. Although first reports indicate that the RNAs bound by ProQ generally differ from those bound by Hfq, recent studies have demonstrated an unexpected overlap of the sets of Hfq and ProQ targets in Salmonella and E. coli, with 30\% of overlapping interactions (Westermann et al., 2019; Melamed et al., 2020). In line with these results, we identified potential 


\begin{tabular}{|c|c|c|c|c|c|c|c|c|}
\hline Strain & WT & $\Delta h f q$ & $\Delta h f q$ & $\triangle p r o Q$ & $\triangle p r o Q$ & $\Delta h f q \Delta p r o Q$ & $\Delta h f q \Delta p r o Q$ & $\Delta h f q \Delta p r o Q$ \\
\hline Plasmid & Control & Control & $h f q$ & Control & proQ & Control & $h f q$ & proQ \\
\hline Growth & $=$ & $\Downarrow$ & $=$ & $=$ & $\Downarrow$ & $\Downarrow$ & $\Uparrow$ & $=$ \\
\hline Virulence & $=$ & $\Downarrow$ & $=$ & $\Downarrow$ & $=$ & $\Downarrow$ & $\Uparrow$ & $=$ \\
\hline Pectinases & $=$ & $\Downarrow$ & $=$ & $\Downarrow$ & $=$ & $\Downarrow$ & $\Uparrow$ & $\Uparrow$ \\
\hline Proteases & $=$ & $\Downarrow$ & $=$ & $\Downarrow$ & $=$ & $\Downarrow$ & 1 & $\Uparrow$ \\
\hline Cellulase & $=$ & $\Downarrow$ & $=$ & $\Downarrow$ & $=$ & $\Downarrow$ & $=$ & $\Uparrow$ \\
\hline Mobility & $=$ & $\Downarrow$ & = & $\Downarrow$ & 二 & $\downarrow$ & $\Uparrow$ & $=$ \\
\hline Adherence & $=$ & $\Uparrow$ & $=$ & $\Uparrow$ & $=$ & 1 & $=$ & $\Downarrow$ \\
\hline hrpN & $=$ & $\downarrow$ & ND & $\downarrow$ & ND & $\downarrow$ & $\uparrow$ & 1 \\
\hline outC & $=$ & $\Downarrow$ & ND & $\Downarrow$ & ND & $\Downarrow$ & $=$ & $\downarrow$ \\
\hline pelE/pelD & $=$ & $\Downarrow$ & ND & $\Downarrow$ & ND & $\downarrow$ & $\hat{\imath}$ & $\downarrow$ \\
\hline prtB & $=$ & $\Downarrow$ & ND & $\sqrt{t}$ & ND & $\downarrow$ & $\hat{\imath}$ & $\Uparrow$ \\
\hline prtc & 二 & 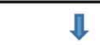 & ND & $\Downarrow$ & ND & $\downarrow$ & $\uparrow$ & 1 \\
\hline celZ & $=$ & $\Downarrow$ & ND & $\Downarrow$ & ND & $\downarrow$ & $\Uparrow$ & $\Uparrow$ \\
\hline kdgK & $=$ & $\Downarrow$ & ND & $=$ & ND & $\sqrt{\downarrow}$ & $=$ & $\downarrow$ \\
\hline flic & $=$ & $\downarrow$ & ND & $\downarrow$ & ND & $\Downarrow$ & $\Uparrow$ & $=$ \\
\hline$b c s A$ & $=$ & 1 & ND & 1 & ND & $\hat{1}$ & $=$ & $\Downarrow$ \\
\hline proQ & $=$ & $\hat{\imath}$ & ND & $\Downarrow$ & ND & $\Downarrow$ & $=$ & $\boldsymbol{1}$ \\
\hline$h f q$ & $=$ & $\Downarrow$ & ND & $=$ & ND & $\Downarrow$ & $\Uparrow$ & $=$ \\
\hline
\end{tabular}

FIGURE 9 | Overview of phenotypes and variation of expression levels associated with the inactivation of proQ and $h f q$. Dash indicates equivalent phenotype (or expression level), up arrow indicates an increase in phenotype (or expression level) and down arrow indicates a decrease in phenotype (or expression level). The double mutant, single mutants and complemented single mutants were compared to the behavior of the wild-type strain whereas double mutant complemented with proQ or hfq were compared to the behavior of the double mutant without any complementation. Expected behavior is indicated in blue, unexpected behavior is indicated in red. ND: Not determined.

ProQ-specific targets such as celZ, but also overlapping targets the $f l i C, b c s A$, pel, and prt genes. Nonetheless, the expression of the target genes was more highly impacted in the double mutant than in each single mutant, indicating putative additive effects of the two proteins. Additionally, analyses of the expression levels of these target genes in the double mutant complemented by each protein highlighted 3 classes of genes: (i) $h r p N$-like genes, whose expression level is restored by Hfq or ProQ, (ii) genes whose expression levels are restored at least partially only by Hfq (e.g., fliC, prtC, outC and pelE), and (iii) genes whose expression levels are partially restored only by ProQ (e.g., $b c s A$ ) (Figure 9). Although further studies aimed at identifying the direct targets of Hfq and ProQ in D. dadantii by in vivo crosslinking will clarify whether the virulence functions governed by ProQ represent a subset of those governed by Hfq, these data reinforce the assumption that the two proteins could have independent competing or complementary roles. ProQ and Hfq could be involved in different regulatory cascades, with branches converging at identical targets. Alternatively, both proteins could interact with the same mRNA. The site of interaction would not necessarily be identical: ProQ recognizes its targets in a sequence-independent manner, through RNA structural motifs found in sRNAs and internal to the coding sequence region or at the $3^{\prime}$ end of mRNAs (Holmqvist et al., 2018); whereas Hfq interacts with nascent transcripts in the $5^{\prime}$-UTR of the target RNA (Kambara et al., 2018). However, the two proteins could outcompete each other at a given terminator since they both have the propensity to bind intrinsic terminators of RNAs (Holmqvist et al., 2016).

Finally, it is noteworthy that an increased level of proQ was measured in the $h f q$ mutant and in the double mutant complemented by proQ. This is of importance because the impact of ProQ on growth and biofilm production is shown to be highly dependent on the amount of ProQ protein produced in the cells. Here, we showed a correlation between a decrease in growth rate and a increase in the amount of proQ and the absence of $h f q$. Furthermore, the decrease level of proQ increases with the inactivation of $h f q$. Finally, the growth defect of the double mutant is complemented by $h f q$ but not by proQ. At this point, we can only speculate, but these observations suggest that in addition to the overlapping, complementary, competing or even 
additive roles of these two RNA chaperones, Hfq could indirectly or directly regulate ProQ production. Further analyses of the complex regulatory network of $\mathrm{Hfq}$ and ProQ should take this possible regulation into account.

\section{DATA AVAILABILITY STATEMENT}

The original contributions presented in the study are included in the article/Supplementary Material, further inquiries can be directed to the corresponding authors.

\section{AUTHOR CONTRIBUTIONS}

$\mathrm{FH}$ and SR contributed to the conception and design of the study. SL performed experiments and the statistical analysis. CV performed the experiments. FH wrote the draft of manuscript. SR and WN contributed to manuscript revision. All authors read and approved the submitted version.

\section{REFERENCES}

Ali Azam, T., Iwata, A., Nishimura, A., Ueda, S., and Ishihama, A. (1999). Growth phase-dependent variation in protein composition of the Escherichia coli nucleoid. J. Bacteriol. 181, 6361-6370. doi: 10.1128/jb.181.20.6361-6370. 1999

Ashby, A. M., Watson, M. D., Loake, G. J., and Shaw, C. H. (1988). Ti plasmid-specified chemotaxis of Agrobacterium tumefaciens C58C1 toward virinducing phenolic compounds and soluble factors from monocotyledonous and dicotyledonous plants. J. Bacteriol. 170, 4181-4187. doi: 10.1128/jb.170.9.41814187.1988

Attaiech, L., Boughammoura, A., Brochier-Armanet, C., Allatif, O., Peillard-Fiorente, F., Edwards, R. A., et al. (2016). Silencing of natural transformation by an RNA chaperone and a multitarget small RNA. Proc. Natl. Acad. Sci. U.S.A. 113, 8813-8818. doi: 10.1073/pnas.1601626113

Bardonnet, N., and Blanco, C. (1992). 'uidA-antibiotic-resistance cassettes for insertion mutagenesis, gene fusions and genetic constructions. FEMS Microbiol. Lett. 72, 243-247. doi: 10.1016/0378-1097(92) 90469-5

Chao, Y., and Vogel, J. (2010). The role of Hfq in bacterial pathogens. Curr. Opin. Microbiol. 13, 24-33. doi: 10.1016/j.mib.2010.01.001

Chaulk, S. G., Smith Frieday, M. N., Arthur, D. C., Culham, D. E., Edwards, R. A., Soo, P., et al. (2011). ProQ is an RNA chaperone that controls ProP levels in Escherichia coli. Biochemistry 50, 3095-3106. doi: 10.1021/bi101683a

Condemine, G., Castillo, A., Passeri, F., and Enard, C. (1999). The PecT repressor coregulates synthesis of exopolysaccharides and virulence factors in Erwinia chrysanthemi. Mol. Plant-Microbe Interac. 12, 45-52. doi: 10.1094/MPMI.1999. 12.1.45

Datsenko, K. A., and Wanner, B. L. (2000). One-step inactivation of chromosomal genes in Escherichia coli K-12 using PCR products. Proc. Natl. Acad. Sci. U.S.A. 97, 6640-6645. doi: 10.1073/pnas.120163297

Dellagi, A., Rigault, M., Segond, D., Roux, C., Kraepiel, Y., Cellier, F., et al. (2005). Siderophore-mediated upregulation of Arabidopsis ferritin expression in response to Erwinia chrysanthemi infection. Plant J. 43, 262-272. doi: 10. 1111/j.1365-313X.2005.02451.X

Duprey, A., Taib, N., Leonard, S., Garin, T., Flandrois, J.-P., Nasser, W., et al. (2019). The phytopathogenic nature of Dickeya aquatica 174/2 and the dynamic early evolution of Dickeya pathogenicity. Environ. Microbiol. 21, 2809-2835. doi: $10.1111 / 1462-2920.14627$

\section{FUNDING}

This work was supported by a grant from the FR BioEnviS. SL received a doctoral grant from the French Ministère de l'Education nationale de l'Enseignement Supérieur, de la Recherche et de l'innovation.

\section{ACKNOWLEDGMENTS}

The authors thank Carlos Blanco for providing the $h f q$ mutant, Pauline Héritier for helpful technical assistance and Georgi Muskhelishvili for helpful discussion. The authors also thank Annie Buchwalter for her careful correction of English language.

\section{SUPPLEMENTARY MATERIAL}

The Supplementary Material for this article can be found online at: https://www.frontiersin.org/articles/10.3389/fmicb. 2021.687484/full\#supplementary-material

Eklund, A. (2016). beeswarm: The Bee Swarm Plot, an Alternative to Stripchart. $R$ package version 0.2.3. Available online at: https://CRAN.R-project.org/ package $=$ beeswarm

Fagard, M., Dellagi, A., Roux, C., Périno, C., Rigault, M., Boucher, V., et al. (2007). Arabidopsis thaliana expresses multiple lines of defense to counterattack Erwinia chrysanthemi. Mol. Plant Microbe Interact. 20, 794-805. doi: 10.1094/ MPMI-20-7-0794

Gonzalez, G. M., Hardwick, S. W., Maslen, S. L., Skehel, J. M., Holmqvist, E., Vogel, J., et al. (2017). Structure of the Escherichia coli ProQ RNA-binding protein. RNA 23, 696-711. doi: 10.1261/rna.060343.116

Holmqvist, E., Li, L., Bischler, T., Barquist, L., and Vogel, J. (2018). Global maps of ProQ binding in vivo reveal target recognition via RNA structure and stability control at mRNA $3^{\prime}$ ends. Mol. Cell 70, 971-982. doi: 10.1016/j.molcel.2018.04. 017

Holmqvist, E., Wright, P. R., Li, L., Bischler, T., Barquist, L., Reinhardt, R., et al. (2016). Global RNA recognition patterns of post-transcriptional regulators $\mathrm{Hfq}$ and CsrA revealed by UV crosslinking in vivo. EMBO J. 35, 991-1011. doi: $10.15252 /$ embj. 201593360

Hommais, F., Oger-Desfeux, C., Van Gijsegem, F., Castang, S., Ligori, S., Expert, D., et al. (2008). PecS is a global regulator of the symptomatic phase in the phytopathogenic bacterium Erwinia chrysanthemi 3937. J. Bacteriol. 190, 7508-7522. doi: 10.1128/JB.00553-08

Jahn, C. E., Selimi, D. A., Barak, J. D., and Charkowski, A. O. (2011). The Dickeya dadantii biofilm matrix consists of cellulose nanofibres, and is an emergent property dependent upon the type III secretion system and the cellulose synthesis operon. Microbiology 157, 2733-2744. doi: 10.1099/mic.0.051003-0

Jiang, X., Sobetzko, P., Nasser, W., Reverchon, S., and Muskhelishvili, G. (2015). Chromosomal "stress-response" domains govern the spatiotemporal expression of the bacterial virulence program. MBio 6:e353-15. doi: 10.1128/mBio.00353-15

Kajitani, M., Kato, A., Wada, A., Inokuchi, Y., and Ishihama, A. (1994). Regulation of the Escherichia coli hfq gene encoding the host factor for phage Q beta. J. Bacteriol. 176, 531-534. doi: 10.1128/jb.176.2.531-534.1994

Kambara, T. K., Ramsey, K. M., and Dove, S. L. (2018). Pervasive targeting of nascent transcripts by Hfq. Cell Rep. 23, 1543-1552. doi: 10.1016/j.celrep.2018. 03.134

Kunte, H. J., Crane, R. A., Culham, D. E., Richmond, D., and Wood, J. M. (1999). Protein ProQ influences osmotic activation of compatible solute transporter 
ProP in Escherichia coli K-12. J. Bacteriol. 181, 1537-1543. doi: 10.1128/jb.181. 5.1537-1543.1999

Lai, J.-L., Tang, D.-J., Liang, Y.-W., Zhang, R., Chen, Q., Qin, Z.P., et al. (2018). The RNA chaperone $\mathrm{Hfq}$ is important for the virulence, motility and stress tolerance in the phytopathogen Xanthomonas campestris. Environ. Microbiol. Rep. 10, 542-554. doi: 10.1111/1758-2229.12657

Leonard, S., Hommais, F., Nasser, W., and Reverchon, S. (2017). Plantphytopathogen interactions: bacterial responses to environmental and plant stimuli: Molecular dialog between phytopathogens and plants. Environ. Microbiol. 19, 1689-1716. doi: 10.1111/1462-2920.13611

Leonard, S., Meyer, S., Lacour, S., Nasser, W., Hommais, F., and Reverchon, S. (2019). APERO: a genome-wide approach for identifying bacterial small RNAs from RNA-Seq data. Nucleic Acids Res. 47:e88. doi: $10.1093 / \mathrm{nar} / \mathrm{gkz} 485$

Link, T. M., Valentin-Hansen, P., and Brennan, R. G. (2009). Structure of Escherichia coli $\mathrm{Hfq}$ bound to polyriboadenylate RNA. Proc. Natl. Acad. Sci. U.S.A. 106, 19292-19297. doi: 10.1073/pnas.0908744106

Lohaus, G., Pennewiss, K., Sattelmacher, B., Hussmann, M., and Hermann Muehling, K. (2001). Is the infiltration-centrifugation technique appropriate for the isolation of apoplastic fluid? A critical evaluation with different plant species. Physiol. Plant 111, 457-465. doi: 10.1034/j.1399-3054.2001.1110405.x

Ma, B., Hibbing, M. E., Kim, H.-S., Reedy, R. M., Yedidia, I., Breuer, J., et al. (2007). Host range and molecular phylogenies of the soft rot enterobacterial genera pectobacterium and dickeya. Phytopathology 97, 1150-1163. doi: 10. 1094/PHYTO-97-9-1150

Maes, M., and Messens, E. (1992). Phenol as grinding material in RNA preparations. Nucleic Acids Res. 20:4374. doi: 10.1093/nar/20.16.4374

Mark Glover, J. N., Chaulk, S. G., Edwards, R. A., Arthur, D., Lu, J., and Frost, L. S. (2015). The FinO family of bacterial RNA chaperones. Plasmid 78, 79-87. doi: $10.1016 /$ j.plasmid.2014.07.003

Melamed, S., Adams, P. P., Zhang, A., Zhang, H., and Storz, G. (2020). RNA-RNA interactomes of ProQ and Hfq reveal overlapping and competing roles. Mol. Cell 77, 411-425. doi: 10.1016/j.molcel.2019.10.022

Meyer, S., Reverchon, S., Nasser, W., and Muskhelishvili, G. (2018). Chromosomal organization of transcription: in a nutshell. Curr. Genet. 64, 555-565. doi: 10.1007/s00294-017-0785-5

Miller, J. G. (1972). Living systems: The organization. Behav. Sci. 17:182. doi: 10.1002/bs.3830170102

Milner, J. L., and Wood, J. M. (1989). Insertion proQ220::Tn5 alters regulation of proline porter II, a transporter of proline and glycine betaine in Escherichia coli. J. Bacteriol. 171, 947-951. doi: $10.1128 / \mathrm{jb} .171 .2 .947-951.1989$

Moran, F., Nasuno, S., and Starr, M. P. (1968). Oligogalacturonide trans-eliminase of Erwinia carotovora. Arch. Biochem. Biophys. 125, 734-741. doi: 10.1016/ 0003-9861(68)90508-0

Ouafa, Z.-A., Reverchon, S., Lautier, T., Muskhelishvili, G., and Nasser, W. (2012). The nucleoid-associated proteins H-NS and FIS modulate the DNA supercoiling response of the pel genes, the major virulence factors in the plant pathogen bacterium Dickeya dadantii. Nucleic Acids Res. 40, 4306-4319. doi: 10.1093/nar/gks014

Pédron, J., Chapelle, E., Alunni, B., and Van Gijsegem, F. (2018). Transcriptome analysis of the Dickeya dadantii PecS regulon during the early stages of interaction with Arabidopsis thaliana. Mol. Plant Pathol. 19, 647-663. doi: $10.1111 / \mathrm{mpp} .12549$

Prigent-Combaret, C., Zghidi-Abouzid, O., Effantin, G., Lejeune, P., Reverchon, S., and Nasser, W. (2012). The nucleoid-associated protein Fis directly modulates the synthesis of cellulose, an essential component of pellicle-biofilms in the phytopathogenic bacterium Dickeya dadantii: Dickeya dadantii Fis protein and biofilm formation. Mol. Microbiol. 86, 172-186. doi: 10.1111/j.1365-2958.2012. 08182.x

R Core Team. (2020). R: A language and environment for statistical computing. Vienna, Austria: R Foundation for Statistical Computing. Available online at: https://www.R-project.org/
Resibois, A., Colet, M., Faelen, M., Schoonejans, E., and Toussaint, A. (1984). phiEC2, a new generalized transducing phage of Erwinia chrysanthemi. Virology 137, 102-112. doi: 10.1016/0042-6822(84)90013-8

Reverchon, S., Meyer, S., Forquet, R., Hommais, F., Muskhelishvili, G., and Nasser, W. (2021). The nucleoid-associated protein IHF acts as a "transcriptional domainin" protein coordinating the bacterial virulence traits with global transcription. Nucleic Acids Res. 49, 776-790. doi: $10.1093 /$ nar/gkaa1227

Reverchon, S., and Nasser, W. (2013). Dickeya ecology, environment sensing and regulation of virulence programme. Environ. Microbiol. Rep. 5, 622-636. doi: 10.1111/1758-2229.12073

Roeder, D. L., and Collmer, A. (1985). Marker-exchange mutagenesis of a pectate lyase isozyme gene in Erwinia chrysanthemi. J. Bacteriol. 164, 51-56. doi: 10.1128/jb.164.1.51-56.1985

Royet, K., Parisot, N., Rodrigue, A., Gueguen, E., and Condemine, G. (2019). Identification by Tn-seq of Dickeya dadantii genes required for survival in chicory plants. Mol. Plant Pathol. 20, 287-306. doi: 10.1111/mpp.12754

Sheidy, D. T., and Zielke, R. A. (2013). Analysis and Expansion of the Role of the Escherichia coli Protein ProQ. PLoS One 8:e79656. doi: 10.1371/journal.pone. 0079656

Shin, G. Y., Schachterle, J. K., Shyntum, D. Y., Moleleki, L. N., Coutinho, T. A., and Sundin, G. W. (2019). Functional characterization of a global virulence regulator $\mathrm{Hfq}$ and identification of Hfq-Dependent sRNAs in the plant pathogen pantoea ananatis. Front. Microbiol. 10:2075. doi: 10.3389/fmicb. 2019.02075

Smirnov, A., Förstner, K. U., Holmqvist, E., Otto, A., Günster, R., Becher, D., et al. (2016). Grad-seq guides the discovery of ProQ as a major small RNAbinding protein. Proc. Natl. Acad. Sci. U.S.A. 113, 11591-11596. doi: 10.1073/ pnas. 1609981113

Smirnov, A., Wang, C., Drewry, L. L., and Vogel, J. (2017). Molecular mechanism of mRNA repression in trans by a ProQ-dependent small RNA. EMBO J. 36, 1029-1045. doi: 10.15252/embj.201696127

Sobrero, P., and Valverde, C. (2012). The bacterial protein Hfq: much more than a mere RNA-binding factor. Crit. Rev. Microbiol. 38, 276-299. doi: 10.3109/ 1040841X.2012.664540

Teather, R. M., and Wood, P. J. (1982). Use of Congo red-polysaccharide interactions in enumeration and characterization of cellulolytic bacteria from the bovine rumen. Appl. Environ. Microbiol. 43, 777-780. doi: 10.1128/aem.43. 4.777-780.1982

Toth, I., van der Wolf, J. M., Saddler, G., Lojkowska, E., Hélias, V., Pirhonen, M., et al. (2011). Dickeya species: an emerging problem for potato production in Europe. Plant Pathol. 60, 385-399. doi: 10.1111/j.1365-3059.2011.02427.x

Tsui, H. C., and Winkler, M. E. (1994). Transcriptional patterns of the mutL-miaA superoperon of Escherichia coli K-12 suggest a model for posttranscriptional regulation. Biochimie 76, 1168-1177. doi: 10.1016/0300-9084(94)90046-9

Updegrove, T. B., Zhang, A., and Storz, G. (2016). Hfq: the flexible RNA matchmaker. Curr. Opin. Microbiol. 30, 133-138. doi: 10.1016/j.mib.2016.02. 003

Vogel, J., and Luisi, B. F. (2011). Hfq and its constellation of RNA. Nat. Rev. Microbiol. 9, 578-589. doi: 10.1038/nrmicro2615

Wagner, E. G. H. (2013). Cycling of RNAs on Hfq. RNA Biol. 10, 619-626. doi: $10.4161 /$ rna.24044

Wang, C., Pu, T., Lou, W., Wang, Y., Gao, Z., Hu, B., et al. (2018). Hfq, a RNA chaperone, contributes to virulence by regulating plant cell wall-degrading enzyme production, type VI secretion system expression, bacterial competition, and suppressing host defense response in Pectobacterium carotovorum. Mol. Plant Microbe Interact. 31, 1166-1178. doi: 10.1094/MPMI-12-17-0303-R

Westermann, A. J., Venturini, E., Sellin, M. E., Förstner, K. U., Hardt, W.-D., and Vogel, J. (2019). The major RNA-binding protein ProQ impacts virulence gene expression in Salmonella enterica Serovar Typhimurium. mBio 10:e02504-18. doi: $10.1128 / \mathrm{mBio} .02504-18$

Wilms, I., Möller, P., Stock, A.-M., Gurski, R., Lai, E.-M., and Narberhaus, F. (2012). Hfq influences multiple transport systems and virulence in the 
plant pathogen Agrobacterium tumefaciens. J. Bacteriol. 194, 5209-5217. doi: $10.1128 / J B .00510-12$

Yuan, X., Zeng, Q., Khokhani, D., Tian, F., Severin, G. B., Waters, C. M., et al. (2019). A feed-forward signalling circuit controls bacterial virulence through linking cyclic di-GMP and two mechanistically distinct sRNAs, ArcZ and RsmB. Environ. Microbiol. 21, 2755-2771. doi: $10.1111 / 1462-2920.14603$

Zeng, Q., McNally, R. R., and Sundin, G. W. (2013). Global small RNA chaperone $\mathrm{Hfq}$ and regulatory small RNAs are important virulence regulators in Erwinia amylovora. J. Bacteriol. 195, 1706-1717. doi: 10.1128/JB.02056-12

Zeng, Q., and Sundin, G. W. (2014). Genome-wide identification of Hfq-regulated small RNAs in the fire blight pathogen Erwinia amylovora discovered small RNAs with virulence regulatory function. BMC Genom. 15:414. doi: 10.1186/1471-2164$15-414$

Conflict of Interest: The authors declare that the research was conducted in the absence of any commercial or financial relationships that could be construed as a potential conflict of interest.

Copyright (c) 2021 Leonard, Villard, Nasser, Reverchon and Hommais. This is an open-access article distributed under the terms of the Creative Commons Attribution License (CC BY). The use, distribution or reproduction in other forums is permitted, provided the original author(s) and the copyright owner(s) are credited and that the original publication in this journal is cited, in accordance with accepted academic practice. No use, distribution or reproduction is permitted which does not comply with these terms. 